\title{
UNIVERSIDAD IBEROAMERICANA
}

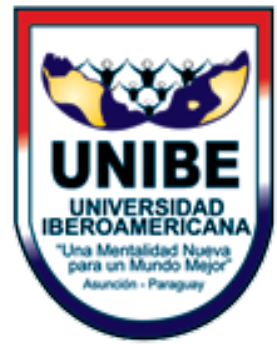

\section{LA UNIVERSIDAD EN EL BICENTENARIO}

\section{UNA APROXIMACIÓN A LA REALIDAD DE LAS INSTITUCiONES DE AsunCión}

INVESTIGADORAS PRINCIPALES

Mg. María Victoria Zavala Saucedo- UNIBE

Lic. María del Carmen González Fornaro-UNIBE

\section{CO-INVESTIGADORAS}

Silvia Negri -Psicopedagogía

Susana Suárez - Psicopedagogía

Roxana Mainero - Ciencias de la Educación

Esther de la Cruz - Ciencias de la Educación

Teresa Ayala - Psicopedagogía

Daisy Patricia Hermosa - Psicopedagogía

Lourdes Espínola - Ciencias de la Educación

Ulises Florentín - Ciencias de la Educación

Alicia González - Psicopedagogía

Laura Raimundo - Psicopedagogía 


\section{PRELIMINARES}

La investigación versó sobre la caracterización de las universidades con sede en Asunción en cuanto a sus dimensiones institucional-organizacional, infraestructura, ofertas, investigación, extensión e innovación, vinculación interinstitucional y financiamiento.

El trabajo se realizó con un diseño no experimental, de tipo descriptivo y con enfoque cuantitativo. El objetivo general fue analizar la realidad de las universidades de la ciudad de Asunción en los ejes de Formación Profesional, Investigación y Extensión, a fin de ofrecer información que oriente la toma de decisiones de los responsables. El estudio se llevó a cabo durante el año 2010 de mayo a diciembre en ocho Instituciones Universitarias con bases o filiales en la ciudad de Asunción que accedieron voluntariamente a formar parte de este trabajo, constituyéndose así en la muestra por conveniencia del estudio. La recolección de los datos se realizó a través de citas prefijadas con las autoridades de cada Universidad, quienes designaron a referentes claves para responder el cuestionario. Los datos se trataron con procedimientos estadísticos y se presentaron graficados.

Entre los resultados más significativos se destacan:

- la preeminencia de instituciones de gestión privada con decir que no son de reciente aparición y se encuentran en el proceso de fortalecimiento y posicionamiento institucional;

- cuentan con las instalaciones necesarias para el desarrollo de sus acciones;

- ofrecen una multiplicidad variada de carreras de grado y el nivel de post grado se halla en desarrollo. Se reconoce un esfuerzo institucional respecto de la investigación y la extensión; las vinculaciones interinstitucionales se concretan a través de convenios y pasantías y los recursos de financiamiento provienen del Tesoro Nacional y diversos aranceles -en las instituciones de gestión estatal- mientras que en las instituciones de gestión privada se generan por medio de los pagos realizados por los usuarios. 


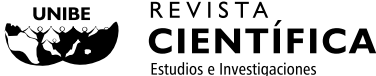

\section{INTRODUCCIÓN}

La creciente valoración de los estudios superiores en una sociedad que prioriza el pensamiento (Morin, 2001), hace de la Universidad como institución, el ámbito por excelencia de la generación del conocimiento. La multiplicidad de los mismos y la unidad de los saberes en el momento de encuentro con la realidad, sustentan un estudio de las distintas ciencias o áreas de la verdad y a la vez, una aplicación a la situación única de cada sociedad y del mundo entero.

Desde sus orígenes, la Universidad tuvo como misión fundamental la búsqueda de la verdad a través de la Investigación (Delors, 1996). Esta misión -de distintas formas- ha ido actualizándose y en la época actual se traduce en la producción de conocimiento científico.

En la realidad Latinoamericana, algunas de las tendencias en el desarrollo de la educación universitaria son: la democratización de la matrícula universitaria, el aumento del número de Instituciones con ofertas de Educación Superior y la multiplicidad de dichas ofertas (UNESCO, 1998), características explicitadas también en el contexto paraguayo, a partir de los años 90 que ha experimentado una creciente aumento de apertura de universidades y una amplia gama de ofertas de formación.

Uno de los principales desafíos de las instituciones universitarias es el desarrollo de la investigación promoviendo la cultura investigativa y la formación de investigadores, por lo cual es preciso ofrecer oportunidades para que profesores y estudiantes abran caminos para este proceso.

En este marco, la UNIBE asumió el reto de esta experiencia brindando las condiciones para realizar esta investigación sobre la Universidad misma como Institución, que tiene por título: La universidad en el bicentenario. Una aproximación a la realidad de las instituciones de Asunción y que se llevó a cabo de mayo a diciembre del año 2010.

Las inquietudes que impulsaron este proceso desarrollado fueron:

- ¿Qué particularidades presentan las Universidades en relación con su infraestructura y equipamiento, la organización y gestión institucionales?

- ¿Cuáles son las características de las ofertas académicas de dichas Instituciones?

- ¿Qué programas o experiencias de Investigación y Extensión e Innovación desarrollan? 
- ¿Cómo se relacionan con otras instituciones, con los organismos gubernamentales, los no gubernamentales y con el sector socio productivo?

- ¿Cómo se financian las Universidades?

Estos interrogantes, llevaron a formular del siguiente modo el problema de investigación: ¿Cómo se caracteriza la realidad de las Universidades de la ciudad de Asunción?

Los objetivos planteados para responder a estos cuestionamientos fueron:

a) Objetivo General

- Analizar la realidad de la Universidades de Asunción en los ejes de Formación Profesional, Investigación y Extensión, a fin de ofrecer información que oriente a la toma de decisiones de los responsables.

b) Objetivos específicos

- Caracterizar las Universidades en relación con su infraestructura y equipamiento, la organización y gestión institucionales.

- Identificar las características de las ofertas académicas de las Instituciones estudiadas.

- Describir las Universidades respecto de la Innovación, de la Investigación y de la Extensión.

- Reconocer el modo de relación que tienen las Instituciones con sus pares, con la Empresa, con la comunidad y con los organismos gubernamentales y no gubernamentales.

- Identificar los recursos de financiamiento de las Universidades objeto de estudio.

La investigación realizada, es de diseño no experimental, de tipo de descriptivo, transversal con enfoque cuantitativo. La técnica empleada fue la encuesta aplicada por medio de un cuestionario estructurado. Este instrumento fue elaborado en base a las dimensiones estipuladas para el trabajo abarcando la totalidad de los indicadores a estudiar. Dicho cuestionario fue validado por juicio de expertos en el que intervinieron docentes e investigadores que no formaron parte de las Instituciones involucradas. 
El estudio se realizó en Instituciones Universitarias con bases o filiales en la ciudad de Asunción durante el año 2010 y contó con la participación de 8 Instituciones Universitarias que accedieron voluntariamente a formar parte de este trabajo constituyéndose así en la muestra por conveniencia del estudio.

La recolección de los datos se realizó a través de citas prefijadas con las autoridades de cada Universidad, quienes designaron a referentes claves para responder el cuestionario. Las respuestas fueron devueltas por correo electrónico o en forma personal.

El procesamiento de los datos se llevó a cabo cargando los mismos en planilla Excel de Microsoft Corporation, inc. para luego ser tratados estadísticamente y graficados para su presentación.

El análisis de los datos recabados, se estructuró inicialmente conforme a los subtemas asignados a cada uno de los estudiantes investigadores, según los objetivos específicos. A efectos de esta publicación los resultados se presentan integrados.

El presente estudio posee una relevancia por un lado; fundamentalmente pedagógica dado que quienes gestionaron y desarrollaron el proceso de investigación fueron los estudiantes orientados por dos profesoras investigadoras. En este sentido se aplicó una estrategia tutorial para iniciar el camino de una cultura investigativa en los alumnos. Por otro lado, sin duda, aporta información de la realidad universitaria de la ciudad de Asunción en lo relacionado a la investigación, la extensión, docencia y las ofertas académicas para una aproximación a la situación de las universidades que formaron parte de la investigación, cuya disponibilidad podrá promover toma de decisiones para desarrollar planes estratégicos. Porta de este modo una relevancia social y académica.

En la primera parte de esta presentación se analizan sucintamente las principales tendencias, desafíos, características y enfoques sobre la Educación Superior en general y la Universidad en particular. En la segunda se comunican los resultados del estudio realizado y cierra el reporte el apartado de las conclusiones y discusión final. 


\section{ESCENARIOS Y PERSPECTIVAS DE LA EDUCACIÓN SUPERIOR}

"La educación superior posee capacidad de adaptación, aunque de forma lenta y conservadora, a cambios sociales de gran alcance. La rápida globalización plantea a las universidades el desafio de si serán capaces de adaptarse a grandes pasos que exige la realidad" Ordoñez (2008, p.38)

En una sociedad cada vez compleja e interconectada como la actual, los sistemas de Educación Superior se enfrentan a nuevos desafíos para incorporar y desarrollar el avance tecnológico, las demandas sociales, la creación y difusión de conocimientos científicos, la conservación y regeneración de la herencia cultural y la globalización que internacionaliza a la sociedad misma. (Morin, E. 2001).

En este sentido, el Comunicado de la Conferencia Mundial sobre la Educación Superior UNESCO (2009) declara: "ante la complejidad de los desafíos mundiales, presentes y futuros, la Educación Superior tiene la responsabilidad social de hacer avanzar nuestra comprensión de problemas polifacéticos con dimensiones sociales, económicas, científicas y culturales, así como nuestra capacidad de hacerles frente". (p.2).

Este escenario exige un análisis reflexivo sobre las funciones que históricamente han sido asignadas a la Universidad de modo a promover una "revisión a fondo, de sus misiones, de su quehacer y de su organización y métodos de trabajo" (Tunnermann, 2003, p. 62).

El cambio experimentado en las sociedades hace emerger nuevas necesidades, replanteándose el proyecto de formación y de universidad que según García Guadilla (1992) lleva a redefinir las funciones en función de un papel estratégico en el desarrollo económico, respecto a la formación de profesionales, la investigación asociada a la producción, las vinculaciones con el Estado y las organizaciones productivas.

Otros de los retos de las políticas que plantea este nuevo escenario, es el del acceso, la equidad y la calidad de la Educación Superior (Mungaray y López, 1996). Si bien los informes de UNESCO dan cuenta de un 
crecimiento sostenido de la matrícula en este nivel, no es suficiente, pues se necesitan buenos resultados que implican una mejora en la pertinencia y la calidad de las ofertas académicas mediante la formación, la investigación y la extensión a la sociedad.

Un proceso que en nuestra región está en fortalecimiento, es el de la evaluación de instituciones y sus ofertas como medio de rendición de cuentas a la sociedad y de búsqueda sostenida de mejores resultados.

Asimismo, la democratización de los estudios universitarios reta a las instituciones a responder a la formación contribuyendo "a los requerimientos básicos de una sociedad moderna, en términos de comportamiento ciudadano, capacidad de integración social y laboral y conocimientos, habilidades y destrezas para responder a las exigencias de los mercados de trabajo" (Idem, p. 7). Esta tendencia produjo el debilitamiento de los umbrales educativos que restó significancia a las certificaciones de grado, exigiendo a los profesionales niveles de formación cada vez más elevados para mantenerse en la carrera profesional. Consecuentemente esto conduce a la democratización de los post grados.

En América Latina, la realidad se torna más desafiante para armonizar la respuesta a las citadas exigencias. Situaciones que tienen que ver con transiciones democráticas, falta de marco legal regulador de la Educación Superior, falta de recursos o de financiación de las universidades para llevar adelante programas y planes de investigación, son algunas de las razones frecuentes y comunes en esta región, que por cierto lentifican el avance hacia una sociedad del conocimiento estructurada y organizada.

La Declaración Mundial sobre Educación Superior en el Siglo XXI: Visión y Acción (UNESCO 1998), sugiere a las instituciones educativas tomar medidas de actualización y mejora en sus planes de estudio a fin de garantizar la excelencia de la investigación y la enseñanza, indicando también la importancia de la gestión e iniciativa en la consecución de apoyo financiero y de recursos provenientes de otros organismos, gubernamentales o no, animados por las sobradas pruebas que la Universidad ha dado de su viabilidad a lo largo de los siglos y de su capacidad para transformarse y propiciar el cambio y el progreso de la sociedad.

Ante esta encrucijada, la Educación Superior tiene que hacer frente a imponentes desafíos, por ello, la misma ha de emprender la transformación y la renovación más radicales que jamás haya tenido por delante, de forma que la sociedad contemporánea, que en la actualidad vive una profunda 
crisis de valores, pueda trascender las consideraciones meramente económicas y asumir dimensiones de moralidad y espiritualidad más arraigadas.

Existen algunas experiencias en países de Europa, como por ejemplo, el estudio realizado por Luis Sanz Menéndez (2003) investigador del Consejo Superior de Investigaciones Científicas (CSIC) de España, donde revela que la vinculación estrecha entre docencia e investigación que se extendió en Europa y Estados Unidos a lo largo del siglo XXI, se inició en un nuevo modelo de estructura: el Departamento Universitario de Investigación en las que se articulaba la docencia con la investigación.

El desarrollo del campo investigativo permite abrir caminos para las experiencias de innovación y desarrollo aplicadas a las tecnologías, a las empresas y a la ciencia en general. Y esto se vincula con las declaraciones de UNESCO (Lovaina, 2009) al presentar la idea de que la calidad de la Educación Superior deberían estimular la innovación y la diversidad disminuyendo la brecha en materia de desarrollo mediante el aumento de la transferencia de conocimiento a través de las fronteras UNESCO (Lovaina, 2009).

Asimismo, todos los documentos referidos a la Educación Superior, reafirman a la investigación como misión y función esencial de la Educación Superior con la consecuente promoción, generación y difusión de conocimientos, debiendo abarcar ámbitos de la ciencia, el arte y las humanidades para lograr elevar la calidad de los educandos.

Pese a este requerimiento, en la realidad de la Educación Superior Latinoamericana, la producción científica y la transferencia de los conocimientos al desarrollo social, sigue siendo una urgencia pendiente.

La Primera Conferencia Regional del Foro Mundial de Educación Superior, Investigación y Conocimiento de la UNESCO, realizada en Porto Alegre. Brasil, 2004, "Convergencias y tensiones en la Educación Superior y la investigación científica en América Latina hoy", manifiesta que "estamos en condiciones de confirmar un balance intranquilizador para las universidades latinoamericanas: el conocimiento, en todas sus manifestaciones y formatos de producción y difusión, no ha sido el actor protagónico de las reformas de los noventa”. (p. 74)

Si bien es cierto que el impacto de los rápidos y bruscos cambios produce incertidumbre, una de las formas de encarar los nuevos retos 
mundialistas puede darse a través de la integración entre las naciones, en procura de soluciones a los emergentes problemas comunes y no comunes de cada país.

Es importante resaltar que la Universidad además de realizar formación de profesionales y llevar adelante investigaciones, debe extenderse con sus estudios superiores, a su entorno. Esta Extensión Universitaria, que la saca de las aulas y la inserta en la sociedad forma parte de las funciones universitarias y de la misión educativa de las instituciones de la Educación Superior. La extensión debe estar presente en las políticas y estrategias de las universidades, las que se deben enriquecer y fortalecer mediante actividades concretas, así como también mantener articulación con las demás funciones académicas. (Bernheim T.C., 2000).

Es así que los programas de extensión se encuentran en una dimensión política y cultural por la relación con la universidad y con la sociedad. Esto le otorga una vinculación refleja con los cambios y tienden a desarrollarse -estos programas- casi autónomamente permitiendo proponer variadas iniciativas o aperturas de socialización.

Otra línea en desarrollo de la Educación Superior, es la relación universidad-empresa que se intensifica y se fortalece a través de los programas de pasantías que las universidades llevan adelante por medio de convenios, becas y acuerdos con dichas organizaciones. Además de dichos programas, Didriksson (1996) apunta que el futuro de la Educación Superior debería incluir la diversificación del financiamiento, la vinculación de las universidades con el sector productivo y la responsabilidad compartida con otras organizaciones sociales.

Asimismo, las Instituciones de Educación Superior tienen la oportunidad de sacar partido de la internacionalización a fin de colmar el déficit de saber y enriquecer el diálogo entre los pueblos y las culturas. La cooperación entre científicos de una misma disciplina trasciende las fronteras y es un instrumento poderoso para internacionalizar la investigación y la tecnología. (Delors, 1998, p. 154)

En este escenario se plantean como medios para fortalecer los vínculos de cooperación entre los países e instituciones, los intercambios de alumnos y profesores, la instalación de sistemas telemáticos de comunicación cada vez más avanzados, la formación de redes interuniversitarias y la creación de centros regionales de excelencia. 
Según Davis (1998) las Universidades tienen que afrontar el nuevo escenario de formación para el ejercicio profesional modificando sus políticas de formación tanto del alumnado como del profesorado. Propone como líneas a considerar las siguientes:

- Nuevo perfil profesional.

- Capacidad para mantener relaciones y trabajar en un contexto de transnacionalidad.

- Inclusión de cursos de post graduación como el doctorado.

- Incorporación de estrategias de inducción y estímulo.

- Generación de espacios que faciliten al personal académico, reflexionar sobre su propia práctica profesional de forma que pueda producirse una formación más vinculada al puesto de trabajo (Zabalza, M. 2002).

Para finalizar, es importante plantear la discusión generada por la UNESCO y la Organización Mundial del Comercio (OMC) respecto de la educación como "bien público" o "bien transable" (Uribe Roldán, 2008). En este sentido, el análisis debe centrarse no en quien presta el servicio, sino en quien lo recibe: "el asunto reside en el hecho de que en cualquiera de los casos, y sea quien sea el prestatario del servicio, éste debe ofrecerse y exigirse en condiciones de calidad y excelencia académica y administrativa (... y) adecuarse a los propósitos y las necesidades de desarrollo del país" (Idem, p.10)

Ante esta mirada de síntesis, la UNESCO (2009) ratifica la prioridad de la Educación Superior como bien público como fundamento de la investigación, la innovación y la creatividad y como estrategia para erradicar la pobreza. Por ello insta a los gobiernos a asumir la responsabilidad y brindar apoyo económico a la Educación Superior.

En el siguiente apartado se tratará de ubicar a la Educación Superior paraguaya en este contexto mundial.

\subsection{Contexto paraguayo}

A partir de la descripción anterior, dentro del espectro de América Latina puede considerarse que "diversos estudios han demostrado la enorme disparidad que se constata con relación a los niveles de desenvolvimiento, grado de articulación con los centros más avanzados de docencia e investigación, cobertura, capacidad de innovación e incidencia sobre el sector productivo de los sistemas de Educación Superior de esta región." (Paraguay, Universidad 2020, 2008, p. 25). 
El proceso de avance depende del contexto nacional del que forma parte la Educación Superior y del desarrollo histórico-institucional de cada universidad. Por ello pueden distinguirse dos grupos de países en relación al desarrollo de la Educación Superior: uno en el que cabe incluir a Méjico, Argentina, Colombia, Brasil y Chile que presentan universidades con niveles de excelencia académica muy por encima de los que caracterizan al común de las universidades latinoamericanas. El otro grupo refiere a las Instituciones universitarias ubicadas en países de menor población, grado de desarrollo y solidez institucional que enfrentan dificultades cada vez mayores para lograr el mejoramiento de la Educación Superior. (Ibidem)

Ubicada en esta heterogeneidad, la Educación Superior paraguaya comparte con los demás características como: sostenida masificación, aumento del número de instituciones, grado de heterogeneidad y dificultades en la capacidad de financiamiento.

Sin embargo, en la búsqueda de la calidad y consciente del rol que le compete en el desarrollo social y económico del país, plantea la urgencia de una Reforma de la Educación Superior.

\subsubsection{Marco SITUACIONAL}

En este proceso de transformación de la Educación Superior paraguaya, hay tendencias compartidas con las ya mencionadas en los apartados anteriores del contexto mundial.

Así se pueden mencionar el aumento cuantitativo de las instituciones universitarias (53 universidades), la diversificación del tipo de instituciones de Educación Superior, el aumento en el número de matriculados en las mismas (168.000 en el 2008 CONACYT $^{1}$ ), el aumento del número y tipo de ofertas, el desarrollo lento de la investigación y extensión universitaria, los varios retos de la Educación Superior y el compromiso de mejorar día a día la calidad educativa.

Entonces surge el interés por ir apinando estrategias a fin de mejorar la calidad como uno de los retos a incluirse en la reforma. Esta búsqueda de la calidad lleva a las Instituciones a la consideración de cuestiones como:

- la articulación e integración en la estructura académica,

- la respuesta de las ofertas a los requerimientos en el campo del conocimiento, de la realidad social y de las profesiones,

${ }^{1}$. En el 2001 eran 99.139 con mayoría de matriculados en el sector de gestión estatal. 
- los académicos como cuerpo docente con acceso a una carrera profesional estructurada,

- la investigación como regeneración y producción de conocimientos, tan propio del nivel Superior de la Educación

- los modelos pedagógicos que replantea roles, espacios, recursos, modalidades y enfoques teóricos,

- la evaluación institucional como mecanismo de aseguramiento y sostenibilidad de la calidad de los servicios educativos

- la extensión como respuesta a la realidad social y como proyección de la Universidad a la sociedad y

- la pertinencia como principio estratégico para la generación de respuestas.

Otro de los componentes del escenario de la Educación Superior paraguaya es la necesidad de consolidar políticas definidas y claras en torno al desarrollo de la misma, así como el de normativas que regulen el funcionamiento y la relación entre el Estado y la autonomía universitaria. Lo señalado tiene como base los diagnósticos (Universidad 2020, 2008 y Diagnósticos y propuestas..., 2005) ya realizados en Paraguay como parte de los procesos de discusión y análisis sobre la Educación Superior con miras a su reforma.

\subsection{Marco Normativo}

En la actualidad, regulan a la Educación Superior paraguaya los siguientes instrumentos legales: La Constitución Nacional, La Ley $\mathrm{N}^{\circ}$ 1.264/98 General de Educación, La Ley de Universidades $N^{\circ} 136 / 93$ y la Ley $N^{\circ}$ 824/96 Protocolo de Integración Educación Educativa sobre reconocimiento de Títulos universitarios para la prosecución de estudios de Post Grado en el Mercosur.

En cuanto a la Constitución Nacional de 1992, en el capítulo VII de la Parte I, los artículos 76 y 79 se refieren a la Educación Superior.

El artículo 76 establece el rol del Estado respecto de la Educación Superior, mencionando que deberá "fomentar", rol éste que puede ser interpretado desde distintas ópticas; ya que puede fomentarse tanto apoyándola o financiándola o auspiciándola -entre otras formasteniendo cada una de estas formas distintos significados, estrategias de concreción e implicancias. Mientras el artículo 79 define por un lado, las tres grandes funciones de la Educación Superior: formación profesional, la investigación y la extensión y por el otro, la organización, gobierno 
y funcionamiento, destacando la autonomía de las instituciones y la libertad de enseñanza y de cátedra.

Por su parte, la Ley General de Educación establece en su Artículo $8^{\circ}$ del Título II Capítulo I el carácter autónomo de las Universidades y de los Institutos Superiores, destacando que en este marco establecerán sus propios estatutos, formas de gobierno y elaborarán sus planes y programas puntualizando que todos estos aspectos lo deben establecer en coherencia con la política educativa nacional y los planes de desarrollo asegurando la existencia de un único sistema educativo nacional de carácter público. En la Sección VI y VII del Título III Capítulo II, se refiere in extenso en los artículos 47 al 55 a la Educación Superior y sus diferentes aspectos. Entre lo dispuesto por esta Ley, mencionamos los siguientes tópicos:

- Necesidad de una Ley de Educación Superior (art.47).

- Definición de las Universidades (art. 48).

- Definición de los Institutos Superiores (art.49).

- Definición de Instituciones de Formación Profesional de Tercer Nivel (art.50).

- Necesidad de priorizar los Institutos de Formación Docente (art. 51).

- Regulación del ejercicio de la profesión (art. 52).

- Pertenencia de las Instituciones de Educación Superior al Sistema Educativo Nacional(art. 53).

- Educación de Post Grado (art. 54 y 55).

La Ley 136/93 de Universidades, dada su especificidad se refiere ampliamente a todo lo concerniente a las Universidades en nuestro país, no obstante su alcance limitado teniendo en cuenta que a partir de la Constitución Nacional y la Ley General de Educación existen otras instituciones que conforman el Nivel de la Educación Superior. Dada la existencia del Tratado del Mercosur que integra a países de la región en carácter de miembros y de asociados, fue necesario el establecimiento de un marco regulatorio regional que permita la movilidad entre los mismos. Así se originó la Ley $\mathrm{N}^{\circ}$ 824/96 Protocolo de Integración Educativa sobre reconocimiento de títulos universitarios de los países parte, para la prosecución de estudios de Post Grado en las universidades del MERCOSUR. Como marco regulatorio, establece normas en relación a duración de carreras, cantidad de horas, procedimientos para el reconocimiento de los títulos, requisitos de admisión de estudiantes, entre otras. En este marco surge el proceso de evaluación y acreditación de carreras universitarias. 
En la actualidad, y acorde con la Ley General de Educación, el Parlamento Paraguayo está abocado al estudio del Proyecto de Ley para la Educación Superior.

Como reflexión final se reafirma lo expresado en el Comunicado de la Conferencia Mundial sobre la Educación Superior, 2009 en estos términos: Los establecimientos de Enseñanza Superior del mundo entero tienen la responsabilidad social de contribuir a reducir la brecha en materia de desarrollo mediante el aumento de la transferencia de conocimientos a través de las fronteras, en particular hacia los países en desarrollo, y de tratar de encontrar soluciones comunes para fomentar la circulación de competencias y mitigar las repercusiones negativas del éxodo de competencia. (p.4).

\section{RESULTADOS}

\section{Datos institucionales Y ORGANIZACIÓN: No 1 AL 10}

\section{Gráfico $\mathbf{N}^{0}$ 1: Tipo de gestión de las Universidades/año de creación.}

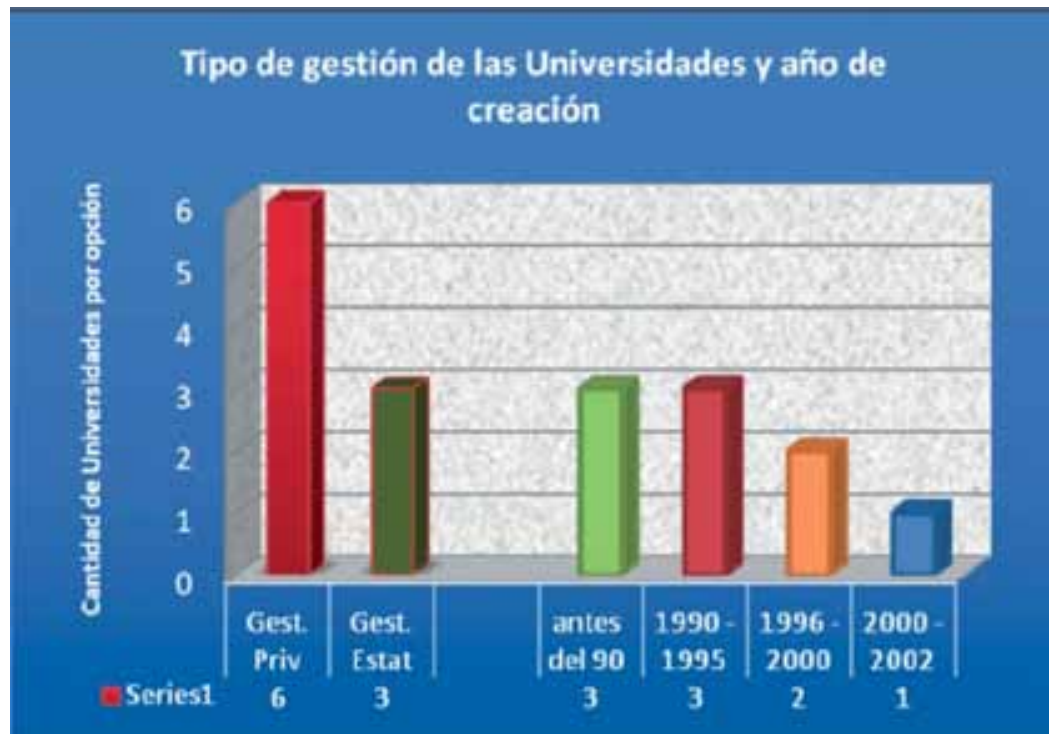

En este gráfico $\mathrm{N}^{\circ} 1$, se observa que seis de las instituciones encuestadas pertenecen a la gestión privada y las tres de gestión estatal, corresponden a la Universidad Nacional de Asunción, siendo tres facultades de la misma. Se las homologó con las universidades privadas aún siendo 
facultades, por el número de alumnos, profesores y tipo de centro de gestión que ejercen. Estas son las que -en el mismo gráfico-se identifican como fundadas antes de 1990, resaltándose que ocho de las instituciones investigadas registran su año de fundación antes del 2001

\section{Gráfico $\mathbf{N}^{0}$ 2: Estructura organizacional: cargos.}

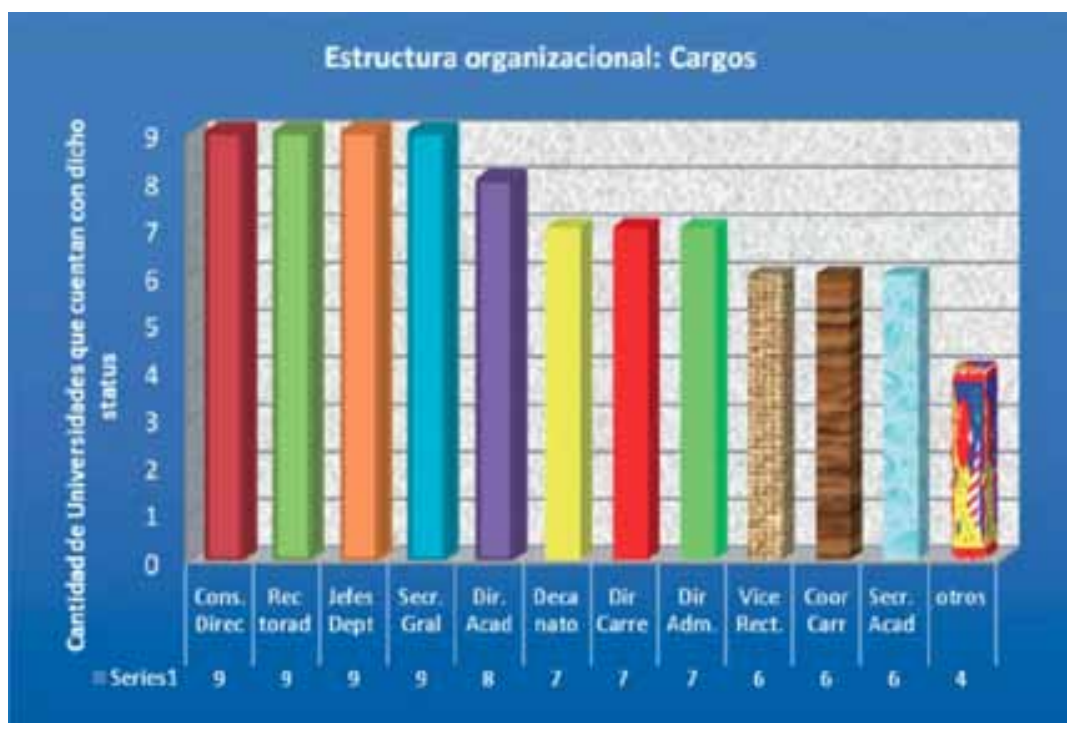

En cuanto a su estructura organizacional, se destaca en el gráfico $\mathrm{N}^{\circ} 2$ ) que el $100 \%$ de las mismas, objeto de este estudio, poseen en su estructura Secretaría Gral., Jefaturas de Departamentos, Rectorado y Consejo Directivo. El resto de los cargos no todas lo presentan. 


\section{Gráfico N 3: Estructura organizacional: Instancias de Gestión.}

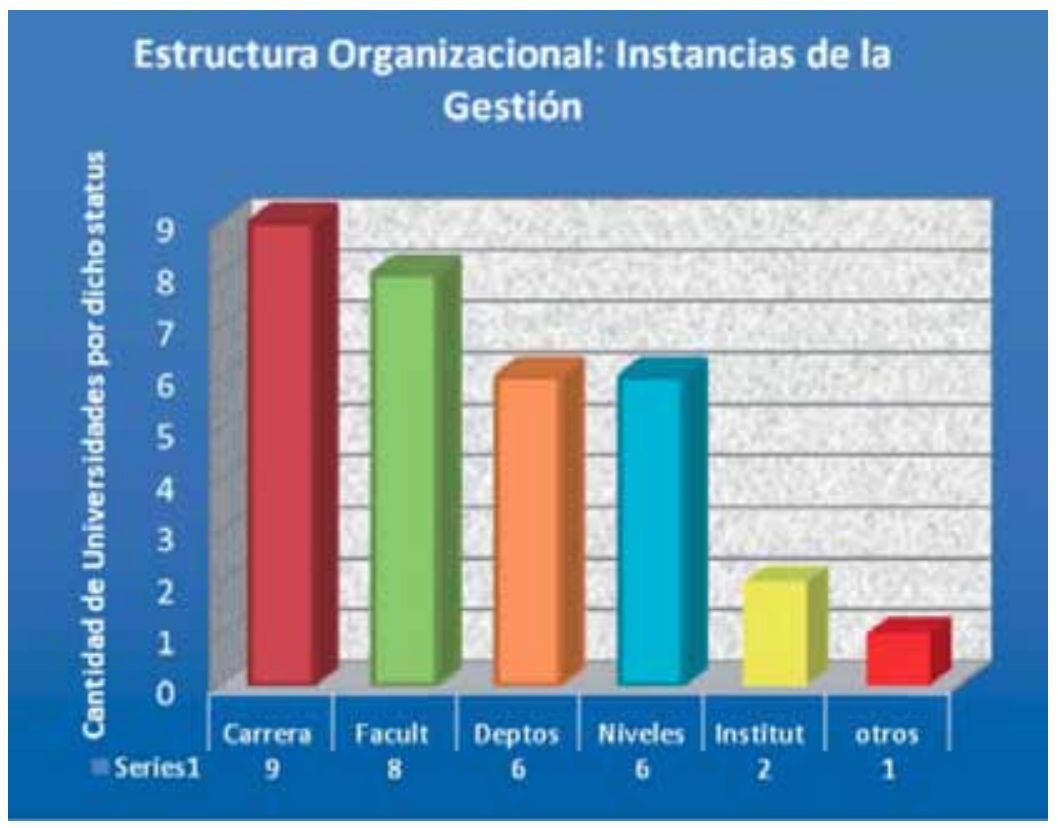

En dicha estructura, la gestión -según se ve en el gráfico $\mathrm{N}^{\circ} 3$ - se realiza mayoritariamente a través de las instancias de las carreras, seguida por la instancia de Facultades. Es de notar que si bien la gestión se concentra en la instancia de las carreras, según vimos en el gráfico anterior, no todas las instituciones cuentan con el cargo de Director de Carreras -siete de las nueve- pero además seis tienen Coordinadores de Carrera. 
Gráfico $\mathbf{N}^{\circ}$ 4: Mecanismos de selección de personal.

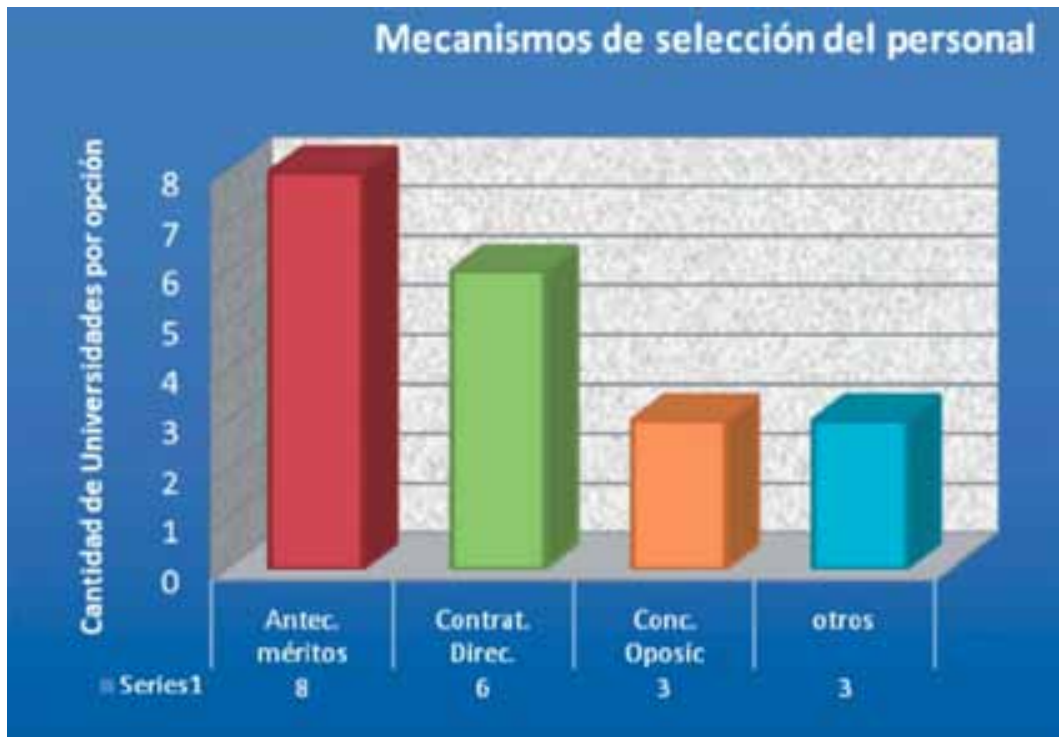

Respecto de los modos por los cuales se selecciona al personal de las instituciones, en el gráfico $\mathrm{N}^{\circ} 4$, la mayoría indica por antecedentes, criterio éste, seguido por la contratación directa. 
Gráfico $\mathrm{N}^{\circ}$ 5: Normativas de funcionamiento.

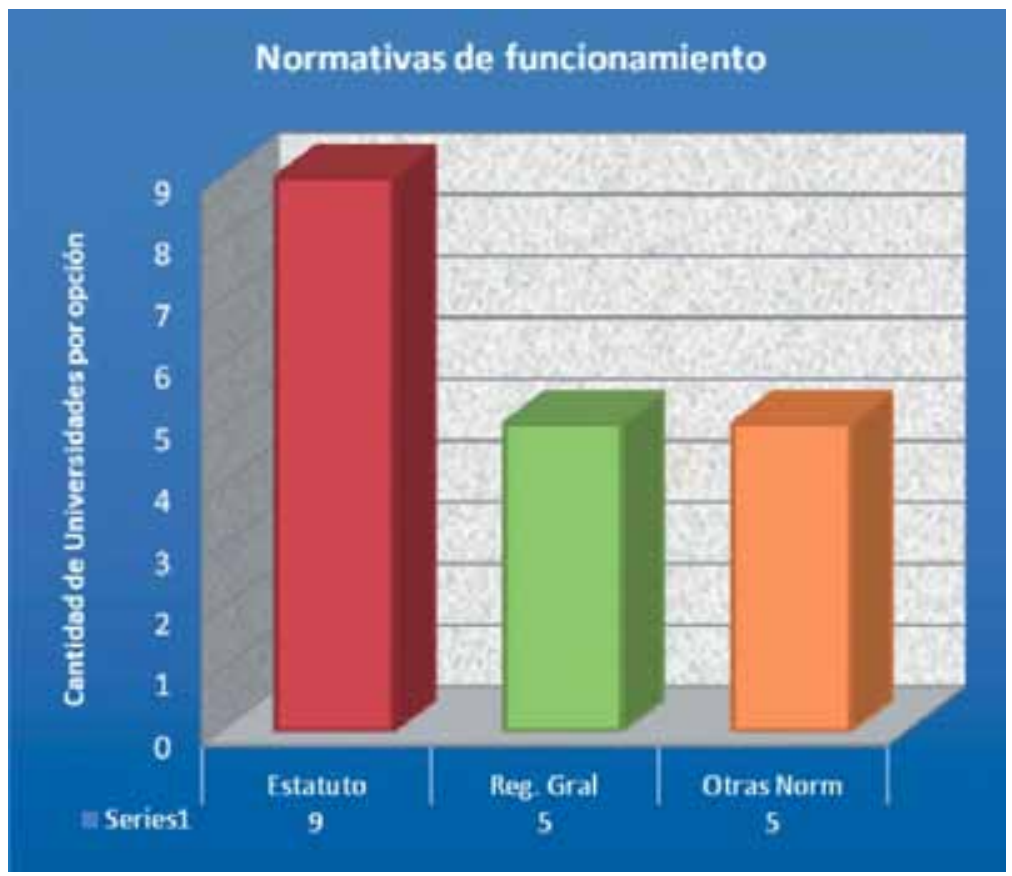

Resalta en el gráfico $\mathrm{N}^{\circ} 5$, que todas las instituciones en su marco normativo, poseen sus Estatutos como eje regulador del funcionamiento.

Se destaca asimismo, que sólo cinco de las nueve instituciones menciona regirse por el Reglamento General. Las mismas marcaron más de una opción. 


\section{Gráfico $\mathbf{N}^{0}$ 6: Sistema de incentivos.}

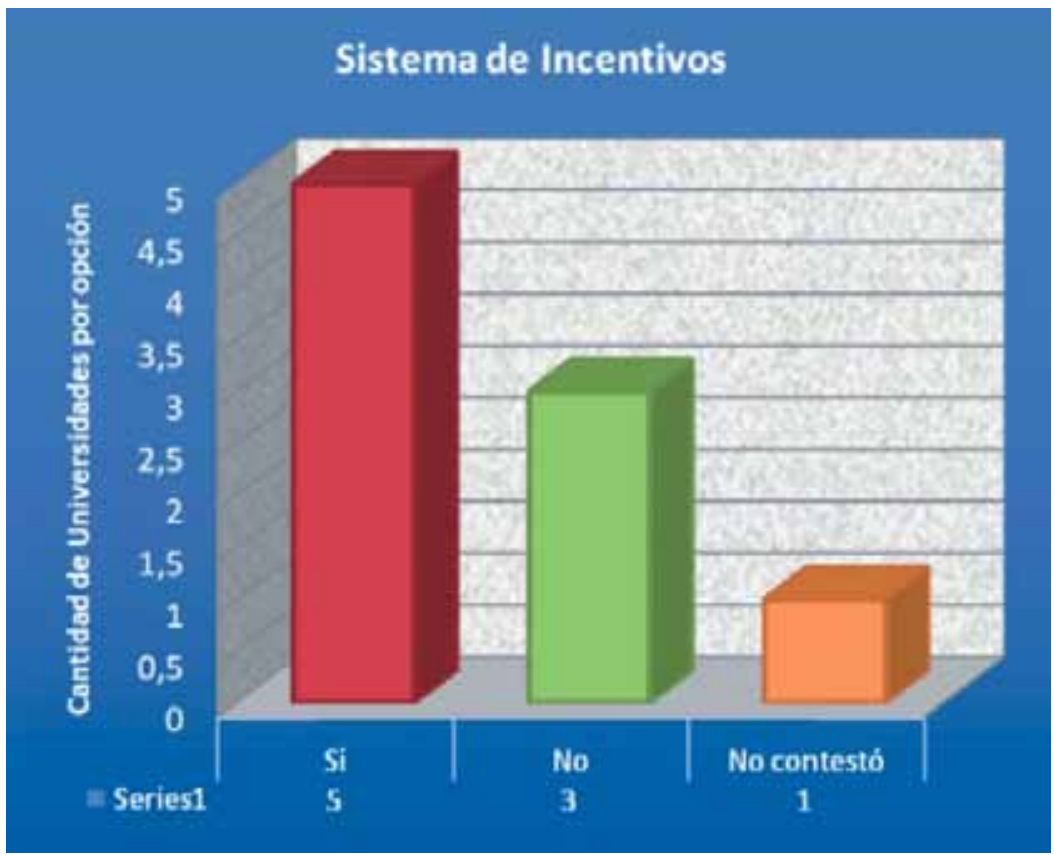

En lo que respecta a sistema de incentivos para los docentes, este gráfico $\mathrm{N}^{\circ} 6$, muestra que cinco de las instituciones declaran aplicarlos. 


\section{DATOS DE INFRAESTRUCTURA}

\section{Gráfico $\mathbf{N}^{0}$ 7: Espacios pedagógicos.}

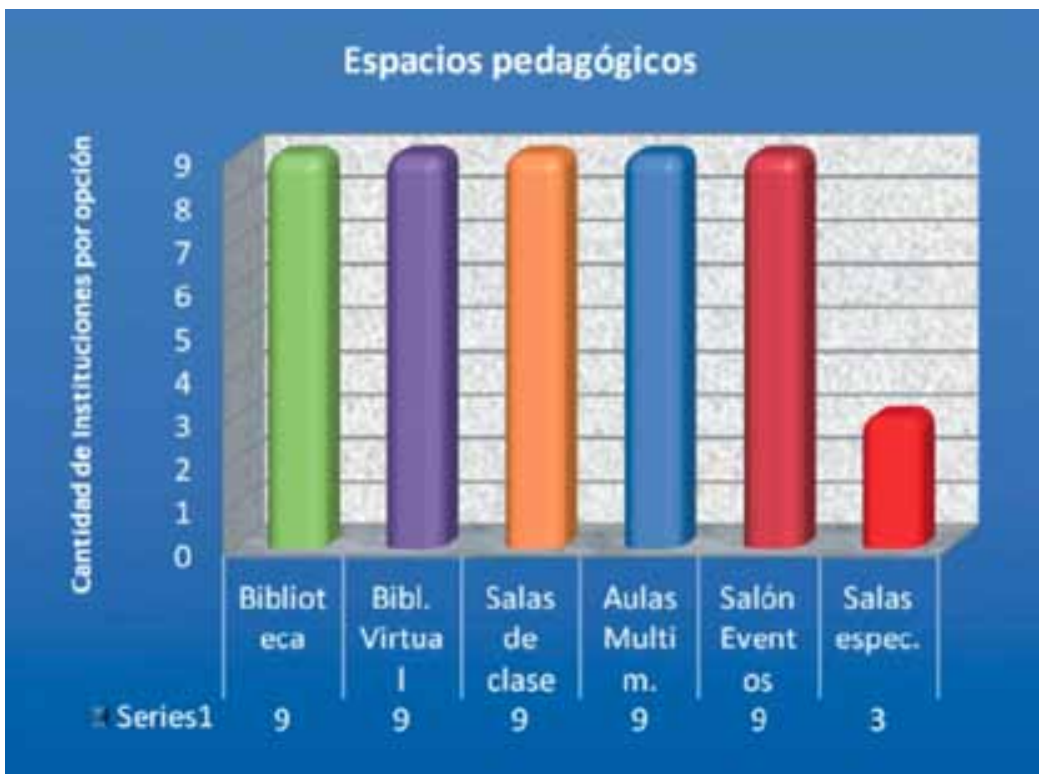

Los datos muestran en el gráfico $\mathrm{N}^{\circ} 7$ que las instituciones poseen los espacios pedagógicos esenciales para el desarrollo del proceso de enseñanza aprendizaje.

Se destaca que las nueve instituciones tienen acceso a Bibliotecas virtuales, lo que indica un posicionamiento de las universidades en las nuevas tecnologías de la sociedad globalizada aplicadas a la educación. 


\section{Gráfico Nº 8: Laboratorios.}

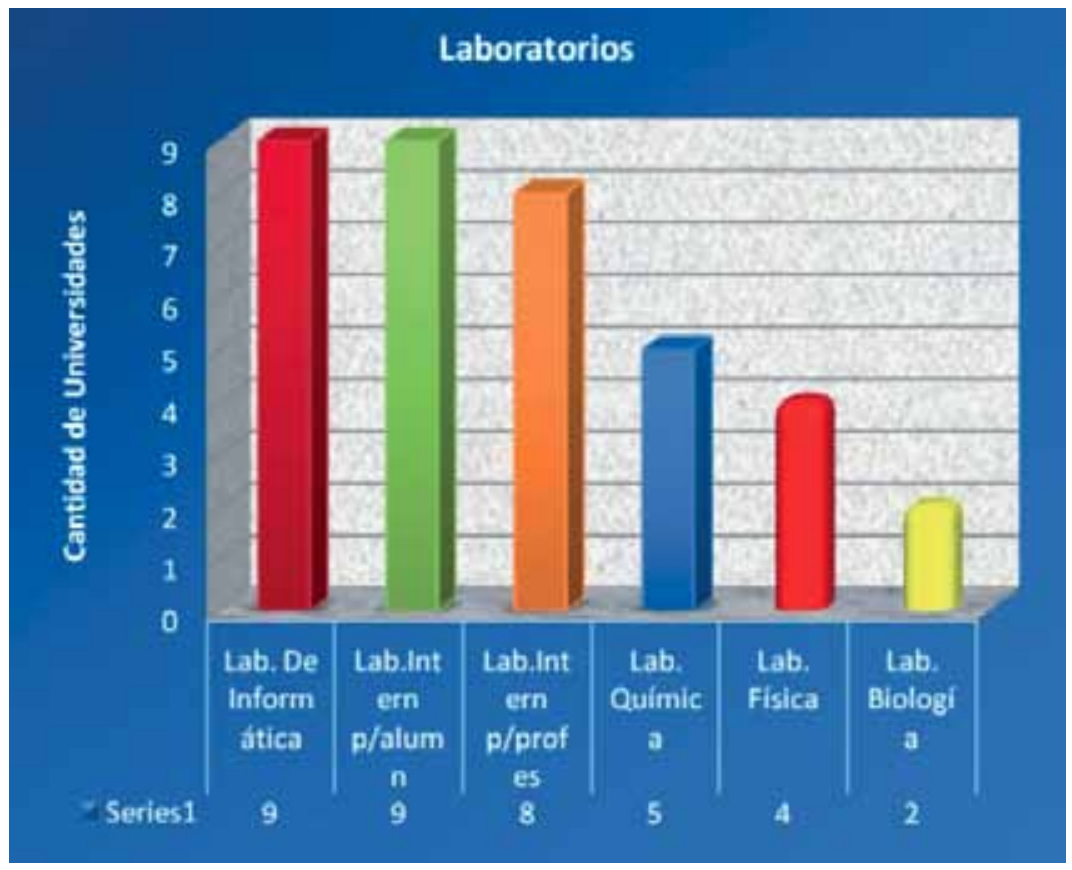

En el Gráfico $\mathrm{N}^{\circ} 8$, se puede verificar esta misma característica dado que los Centros estudiados cuentan con Laboratorios de Informática como espacio específico y como recurso de aprendizaje y enseñanza para docentes y alumnos.

La existencia de los otros Laboratorios especializados, hace referencia a las facilidades que ofrecen según la naturaleza de las carreras, por ello no todas las instituciones cuentan con ellos. 


\section{Gráfico Nº 9: Espacios de gestión.}

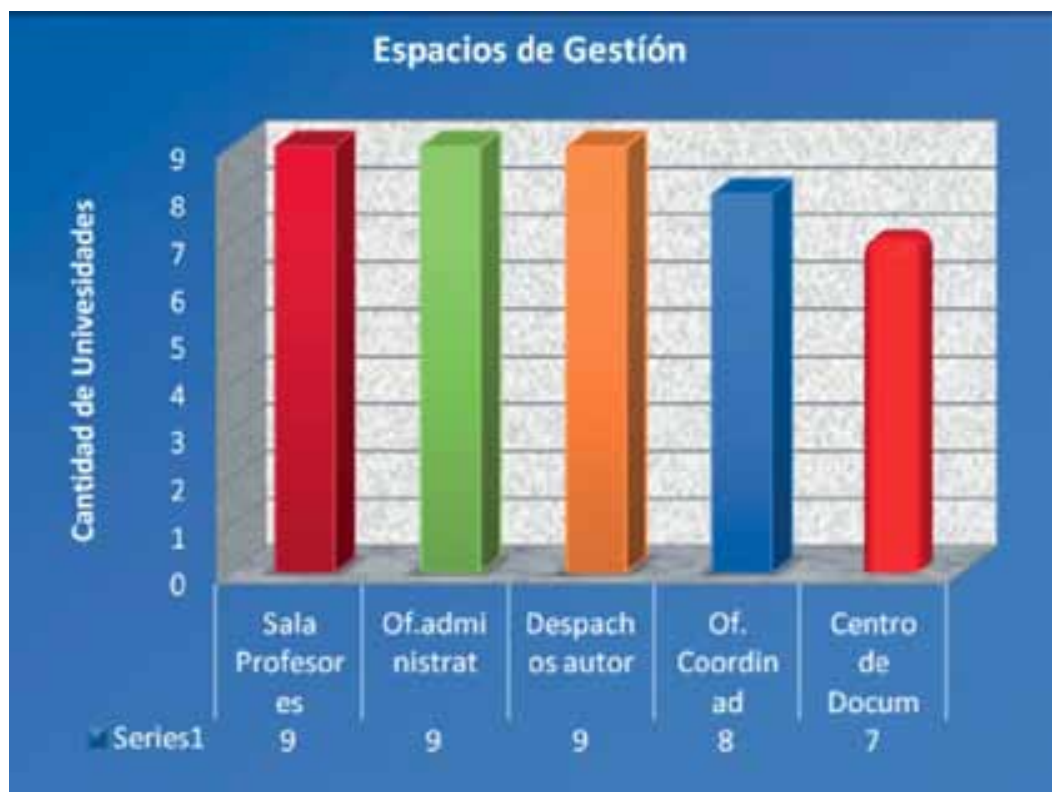

Como puede observarse en el gráfico $\mathrm{N}^{\circ} 13$, los espacios de gestión evidencian la estructura organizativa de las Universidades, lo cual indica que se le da el lugar a los responsables de las acciones de gestión tanto directiva, administrativa como pedagógicas.

Estos datos muestran que las universidades ofrecen un escenario adecuado a los usuarios de los diferentes servicios que se prestan. 
Datos de las ofertas de Grado $\mathrm{N}^{\circ} 10$ a 12

Gráfico $N^{\circ}$ 10: Ofertas de grado por universidad $I$.

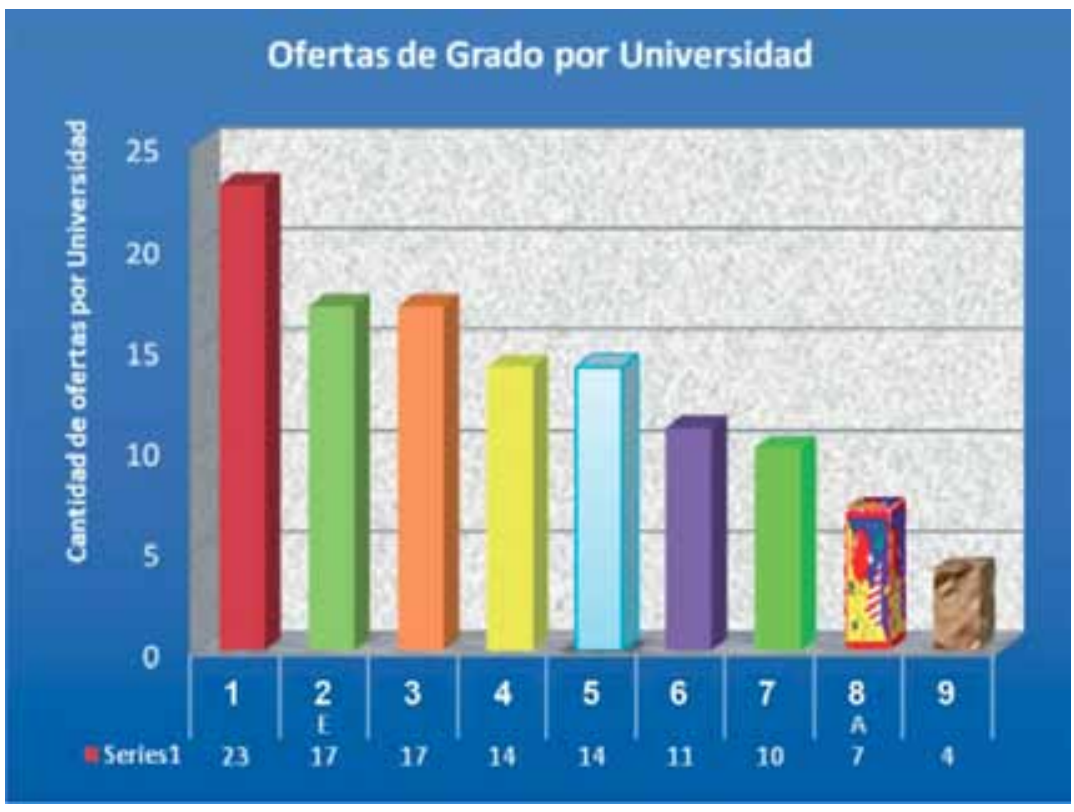

El Gráfico $\mathrm{N}^{\circ} 10$ muestra la cantidad de carreras de grado en distintas áreas (ver Anexo I) ofrecidas por cada institución. 


\section{Gráfico $\mathrm{N}^{\circ}$ 11: Ofertas de grado por universidad II.}

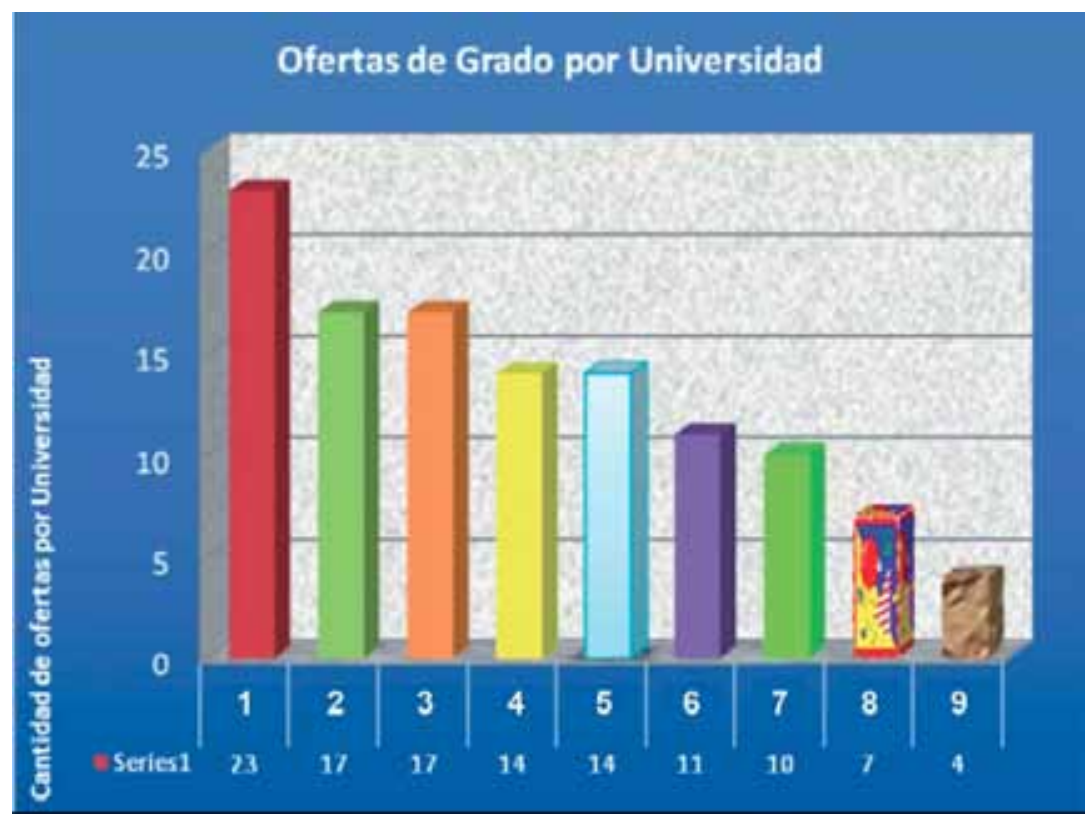

Entre las ofertas, como se observa en el Gráfico $\mathrm{N}^{\circ} 11$, se destacan las Tecnicaturas desarrolladas en cuatro de las nueve instituciones. Cabe aclarar que las mismas no son carreras del nivel de grado, pero cubren una demanda educativa.

Como se ve, son pocas en número dado que este nivel de la Educación Superior es propio -aunque no excluyente-de los Institutos Profesionales del Tercer Nivel. 


\section{UNIBE, REVISTA}

Gráfico $\mathrm{N}^{\circ}$ 12: Carreras de grado por áreas de conocimiento.

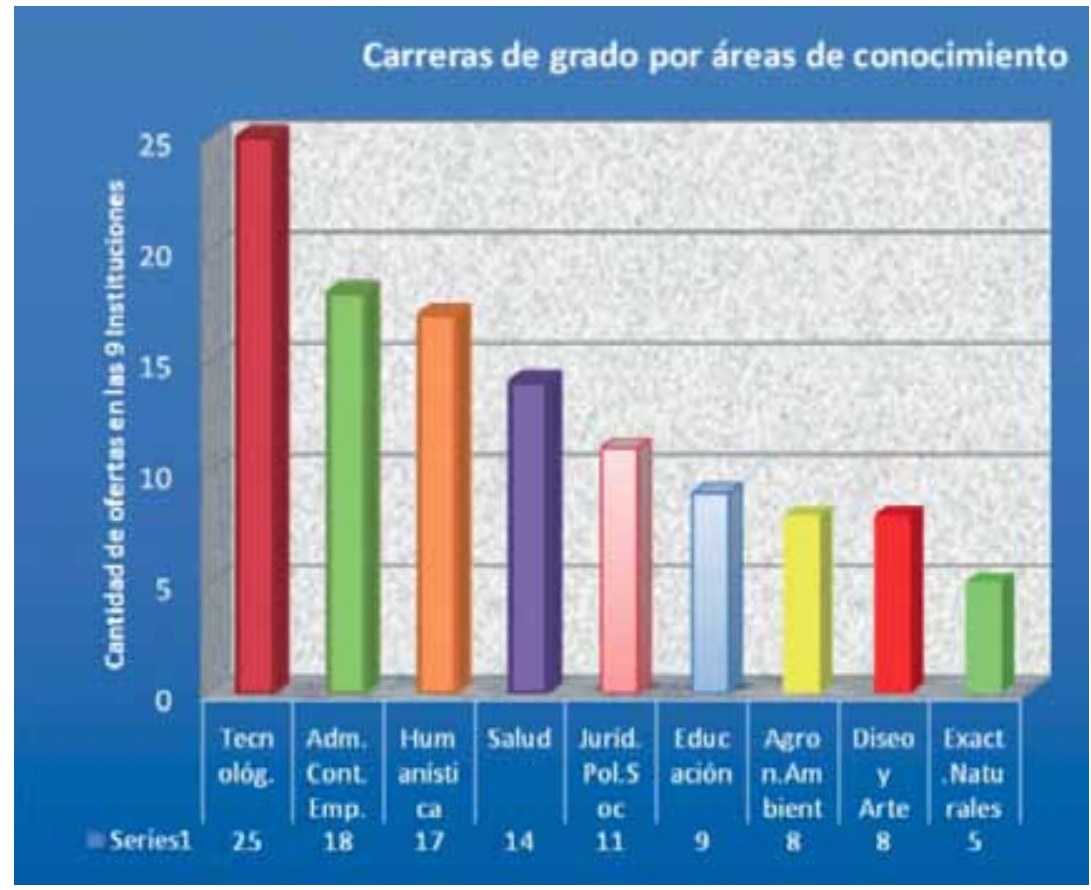

En el Gráfico $\mathrm{N}^{\circ} 12$ se presentan las ofertas de grado por especialidad. Se destaca que la mayor cantidad de carreras se concentra en el área tecnológica que incluye las Ingenierías Civil, Electrónica, Mecánica, Eléctrica, Mecatrónica y las del área de Sistemas Informáticos.

Es importante señalar que el área de Agronomía y Ciencias Ambientales, cuenta tan sólo con 8 carreras siendo el sector agropecuario la base de la economía nacional.

También resalta que las áreas de Administración y Contabilidad, Humanística y Jurídico-Política, agrupan en total 46 carreras que corresponden al sector servicios. Sin embargo las carreras de Salud y Educación -considerados servicios prioritarios- no presentan el mismo desarrollo que las anteriormente mencionadas. 


\section{Datos de las OfERTAS de POST GRAdo $N^{\circ} 13$ a 19}

\section{Gráfico $\mathbf{N}^{\circ}$ 13: Diplomados ofrecidos.}

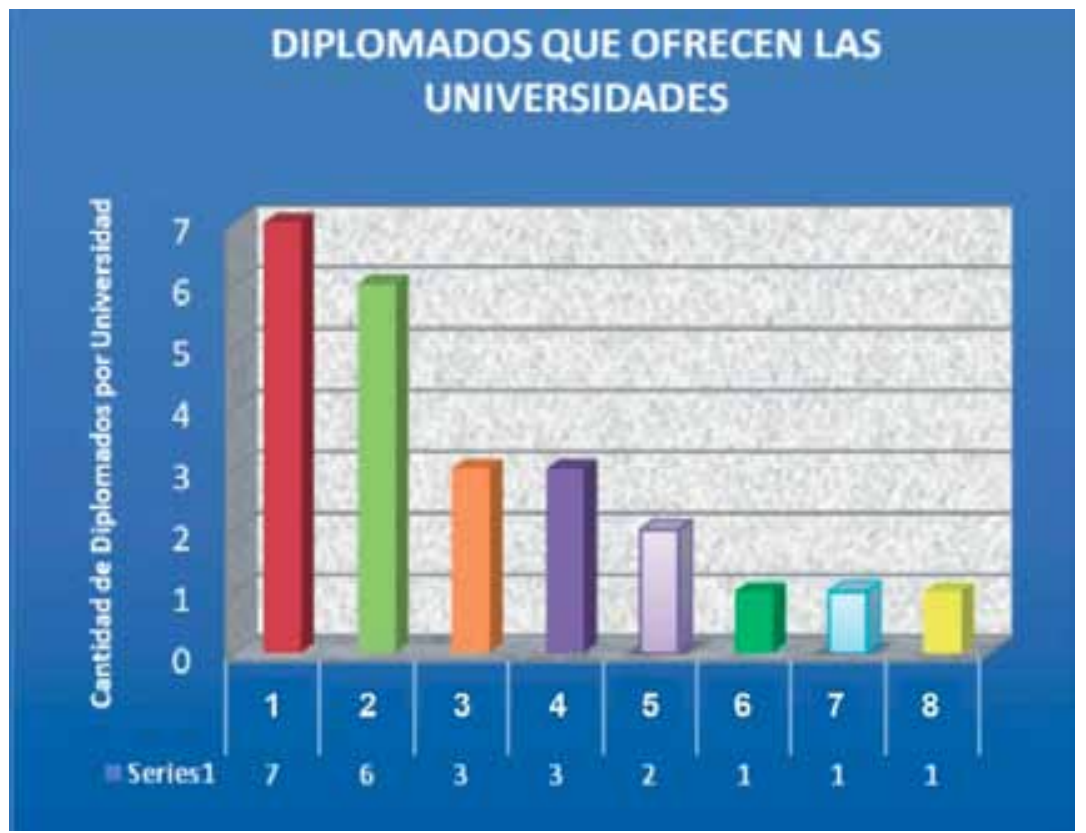

Resalta en los datos del Gráfico $\mathrm{N}^{\circ} 13$, que a excepción de una, las instituciones ofrecen cursos de Diplomado como parte de los Post Grados.

Se destaca la variedad de ofertas que está a disposición de los interesados y que se concentran mayoritariamente en dos de las instituciones. 
Gráfico $N^{\circ}$ 14: Especializaciones que ofrecen las universidades.

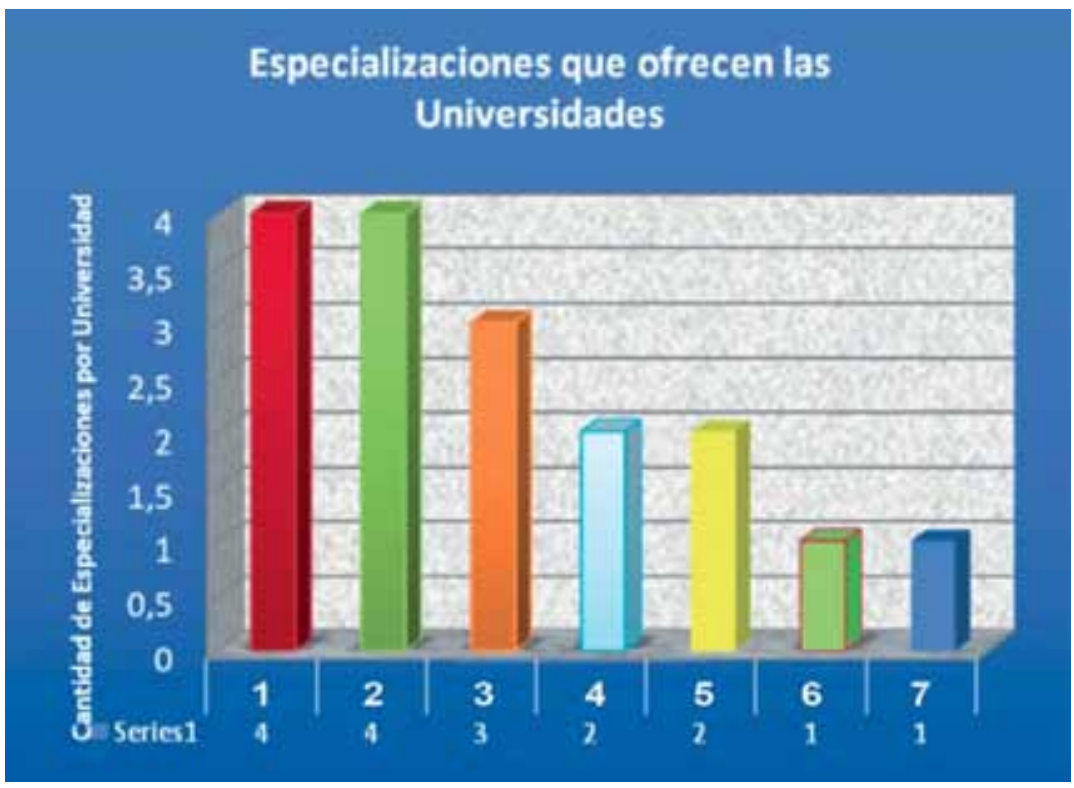

En cuanto a las Especializaciones de Post Grado, se puede ver en el Gráfico $\mathrm{N}^{\circ} 14$, que disminuye el número de instituciones y la cantidad de ofertas con relación a los cursos de Diplomados. 


\section{Gráfico $\mathrm{N}^{\circ}$ 15: Materias ofrecidas.}

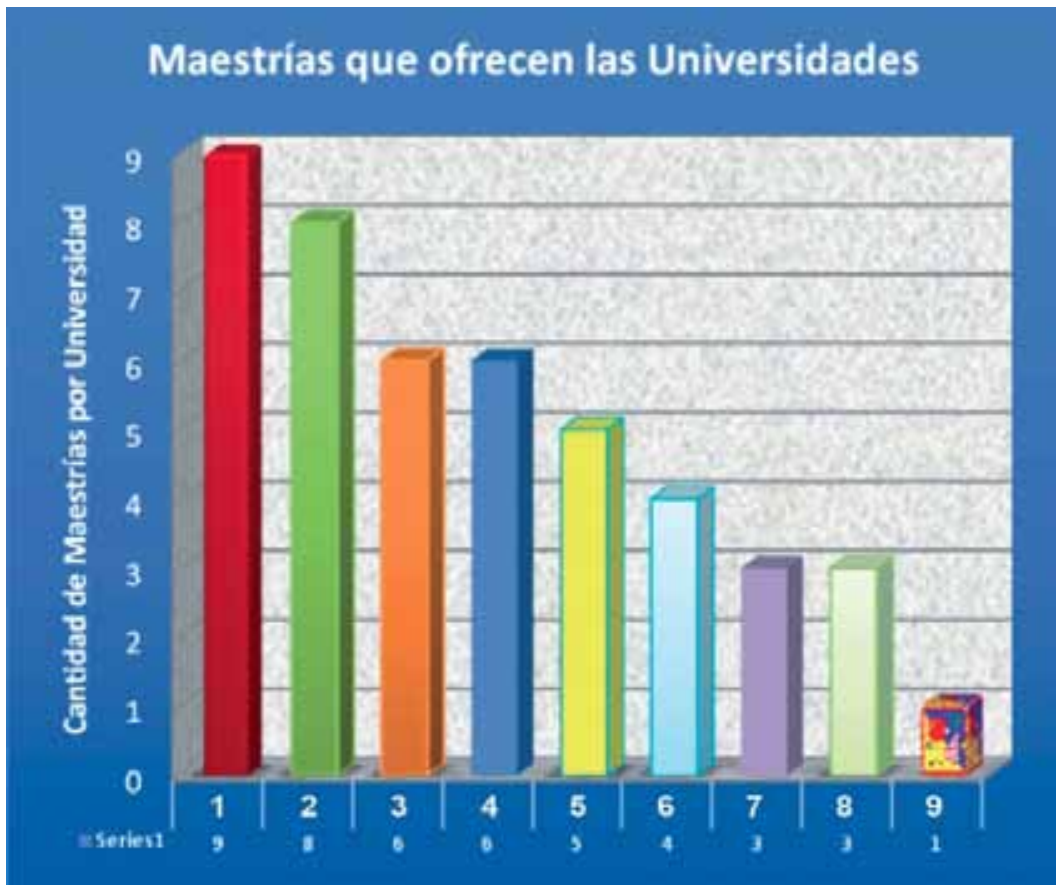

Se evidencia en el gráfico $\mathrm{N}^{\circ} 15$ que la oferta del nivel de Maestría lidera las de Post Grado en cuanto a cantidad pues todas las instituciones estudiadas la ofrecen 


\section{Gráfico $N^{\circ}$ 16: Doctorados ofrecidos.}

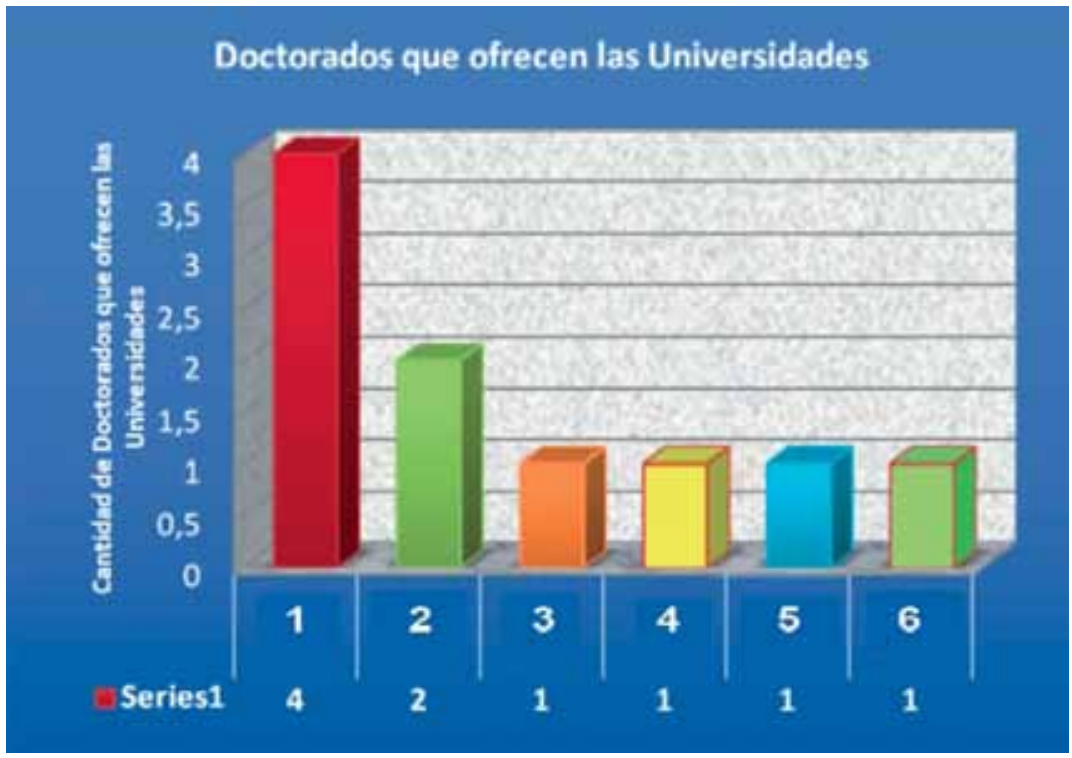

Se nota en el gráfico $\mathrm{N}^{\circ} 16$ que los cursos de Doctorado, se encuentran en proceso de aumento cuantitativo en cuanto a ofertas. Resalta que un solo Centro ofrece cuatro alternativas. 


\section{Gráfico $N^{\circ}$ 17: Especializaciones ofrecidas por áreas.}

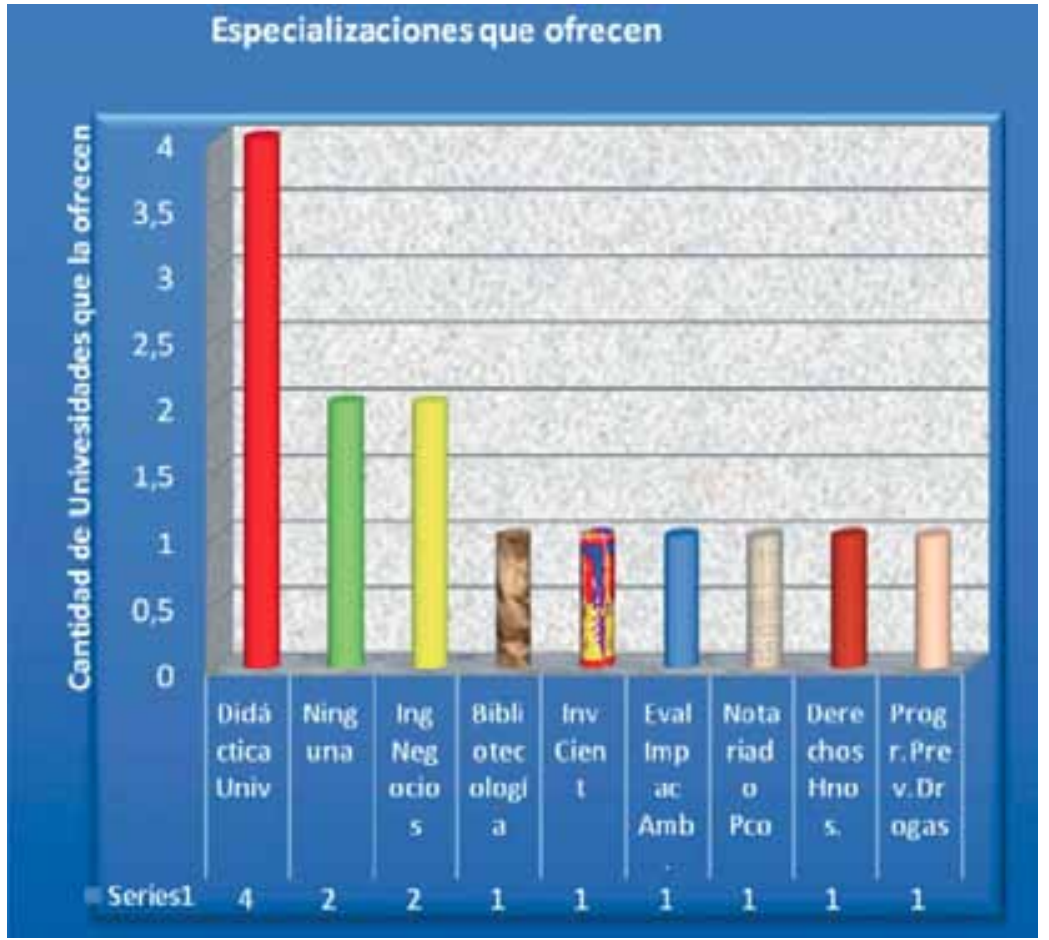

En cuanto a las áreas en la Especialización se destaca en el Gráfico $\mathrm{N}^{\circ}$ 17, que la Didáctica de la Educación Superior, es la de mayor oferta.

No obstante, resalta que hay nueve áreas de Especializaciones en las distintas instituciones lo cual da cuenta de la importancia atribuida a estos cursos. 
Gráfico $\mathrm{N}^{\circ}$ 18: Maestrías ofrecidas por área.

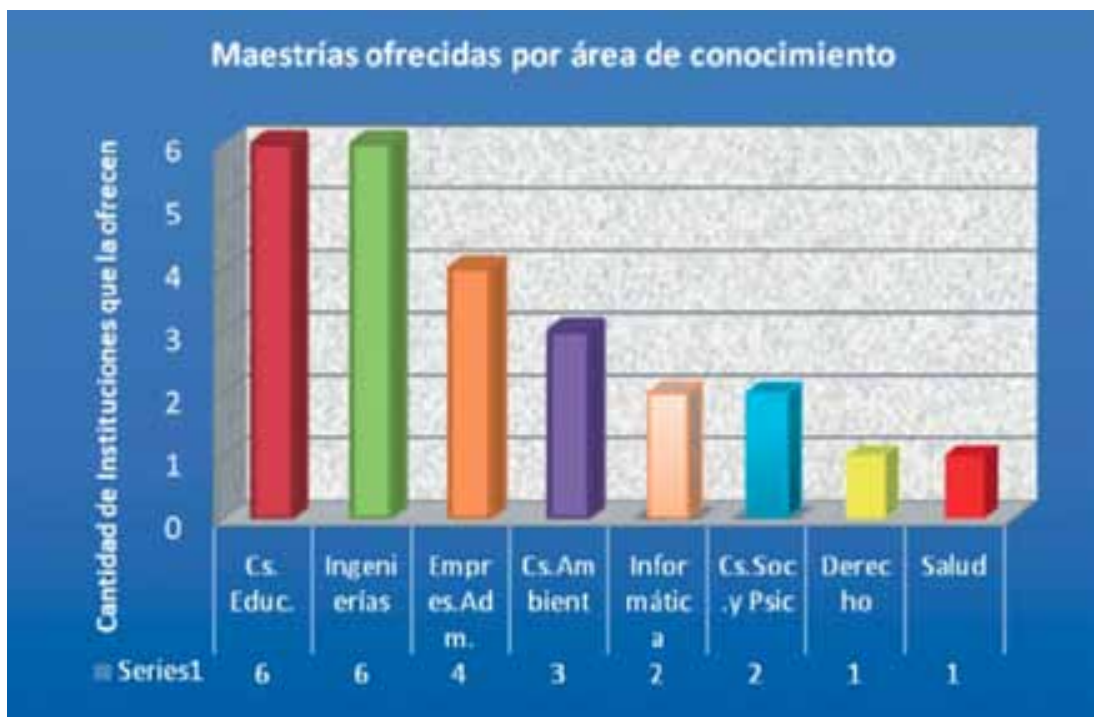

Las áreas de mayor oferta, como se visualiza en el Gráfico $\mathrm{N}^{\circ} 18$, en el nivel de Maestría son las de Educación e Ingenierías. En este nivel, además de éstas, se ofrecen seis áreas lo que reitera la relevancia que está adquiriendo el nivel de Post Grado. 


\section{Gráfico $N^{\circ}$ 19: Doctorados por área.}

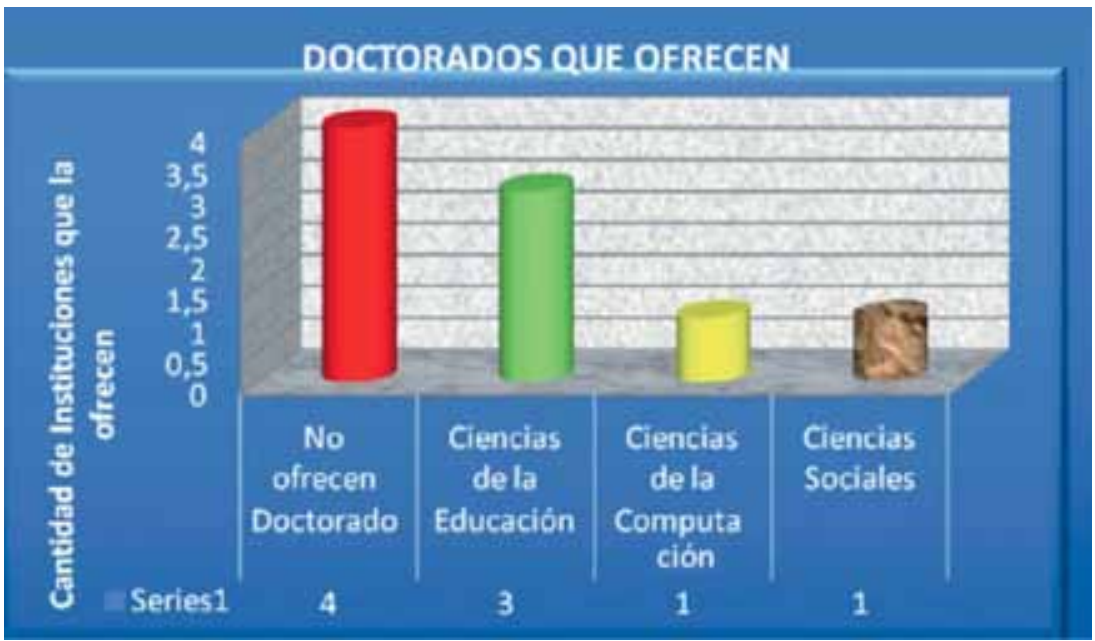

El número de ofertas en el nivel de Doctorado, según el Gráfico $\mathrm{N}^{\circ} 19$, está en crecimiento. 


\section{UNIBE \\ Datos REFERENTES A INVESTIGACIÓN $\mathbf{N}^{\circ} 20$ A 25}

Gráfico $N^{\circ} 20$ : Instancias organizacionales de gestión de la investigación.

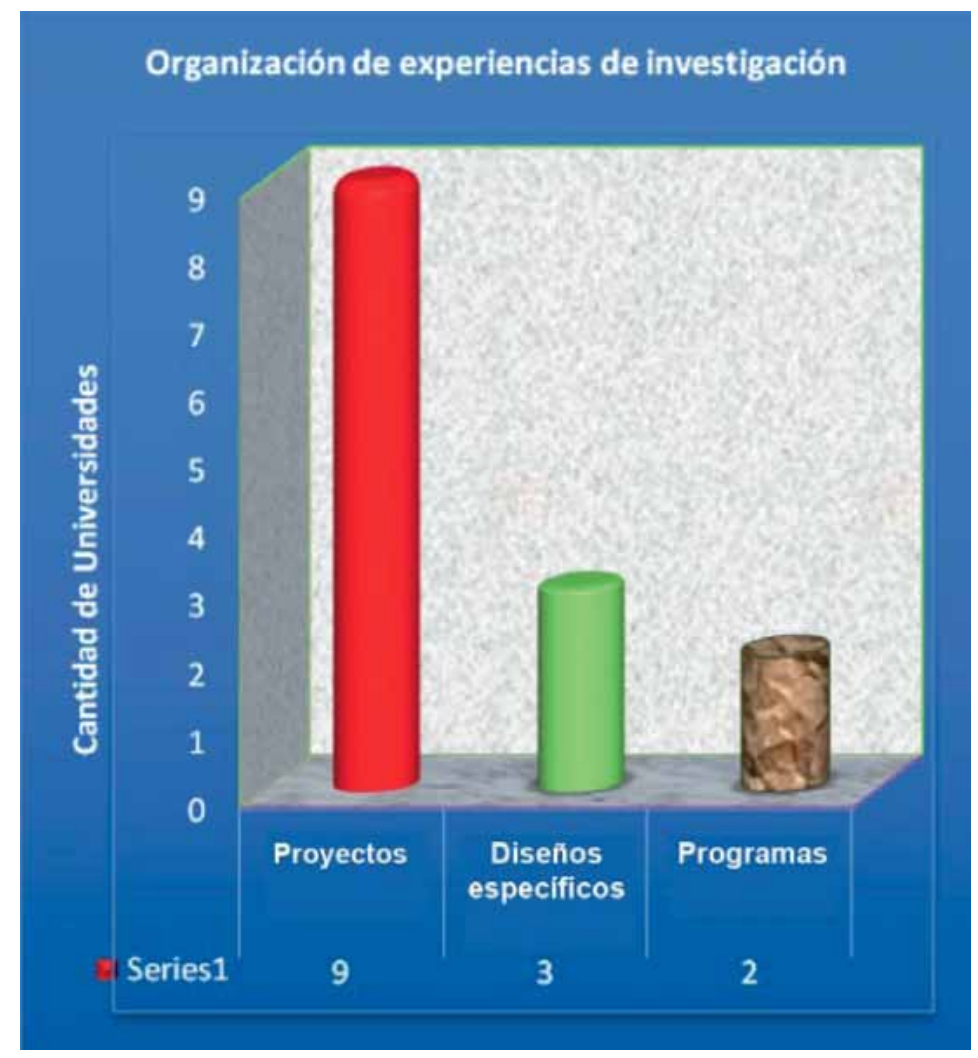

El gráfico $\mathrm{N}^{\circ} 20$ muestran que las 9 Universidades estudiadas estructuran sus actividades de investigación en Proyectos, asimismo, 2 de ellas además mencionan que estos Proyectos forman parte de Programas lo cual indica sostenibilidad, articulación y recursos para el desarrollo.

Otro dato resaltante es que 8 de las Universidades cuentan con un Departamento de Investigación desde el cual se gestionan dichas actividades, dándole un posicionamiento en la estructura organizacional y una entidad que se proyecta en la imagen institucional interna y externa. 
Gráfico $\mathbf{N}^{\circ}$ 21: Instancias organizacionales de gestión de la investigación.

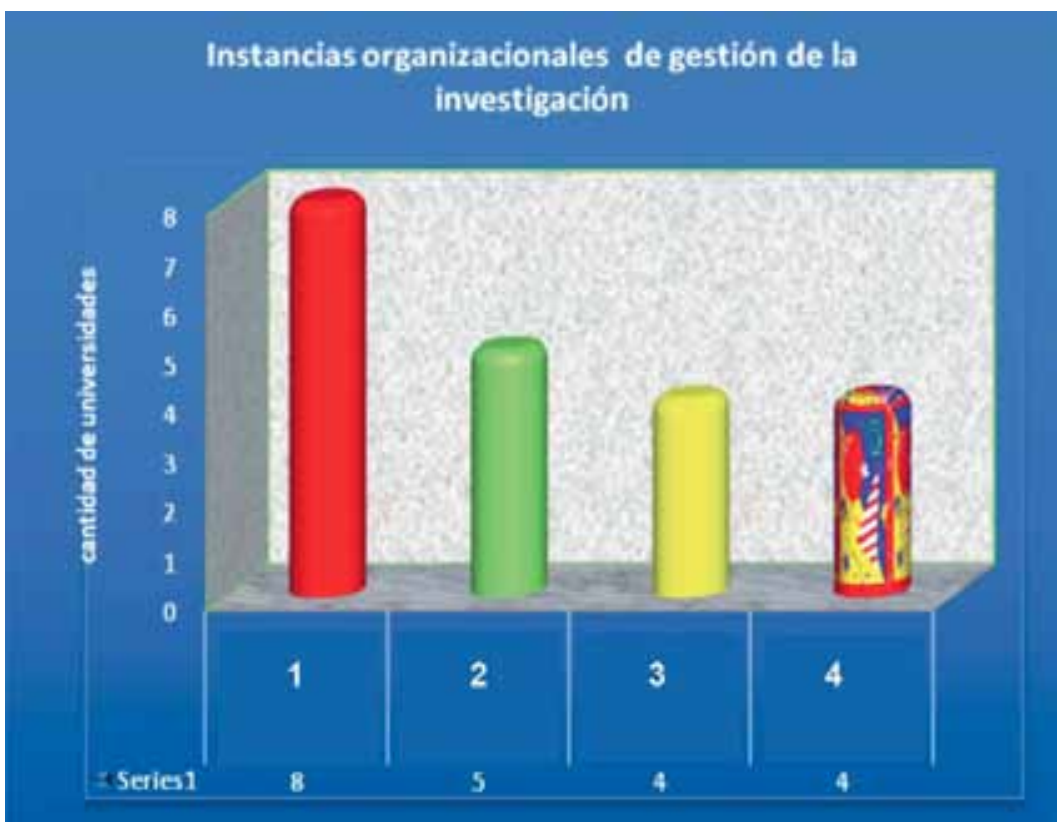

Se destaca también en el Gráfico $\mathrm{N}^{\circ} 21$, que 5 Instituciones declararon gestionar la investigación a través de profesores evidenciando el esfuerzo por promover esta actividad tan propia de la Universidad. Asimismo 4 centros manifestaron contratar a especialistas externos para tal objetivo lo que indica una gestión ajena a la estructura organizacional. 


\section{Gráfico $N^{\circ}$ 22: Experiencias de investigación}

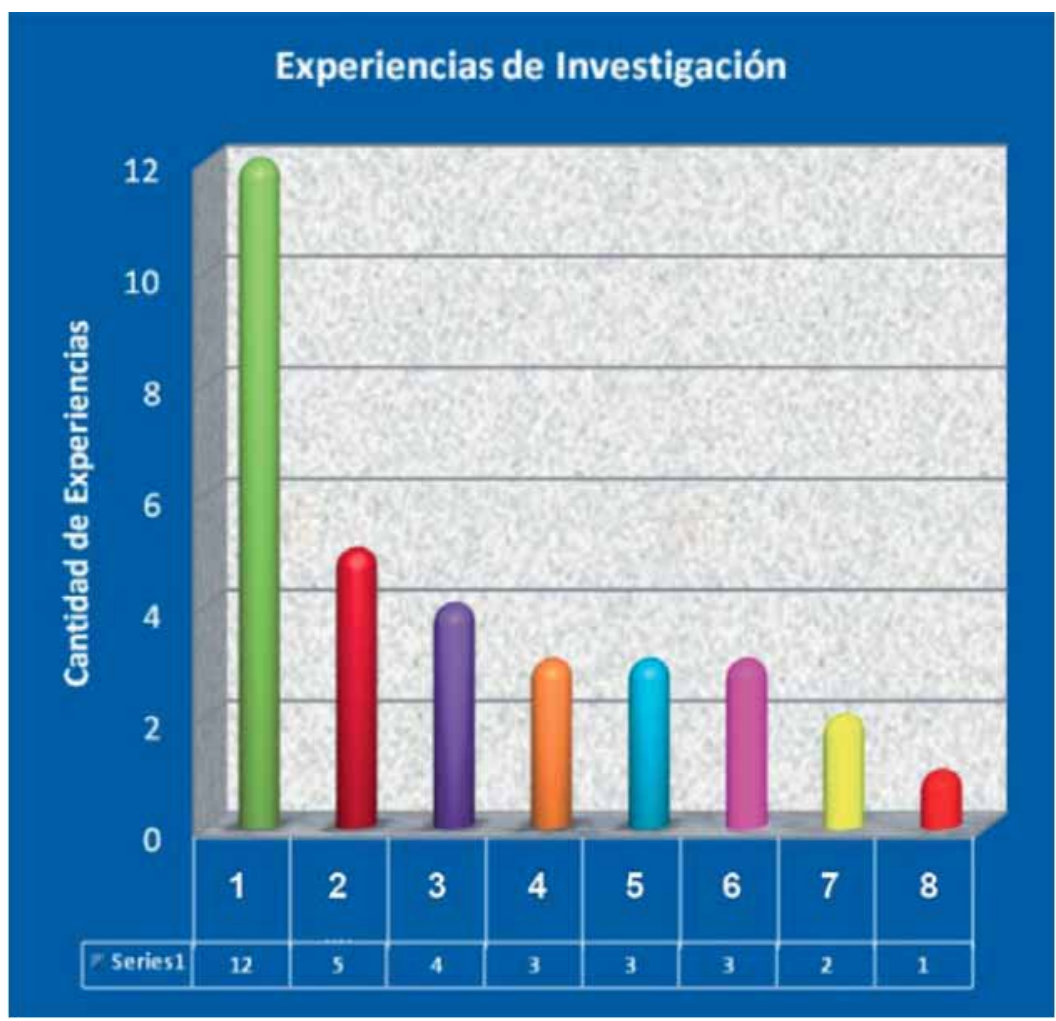

En los datos del Gráfico $\mathrm{N}^{\circ} 22$ se destaca que la Facultad 1 es la institución universitaria que reconoce mayor cantidad de experiencias de investigación.

Las demás instituciones también reconocen tener experiencias en el área aunque en menor cantidad. 


\section{Gráfico $\mathbf{N}^{\circ}$ 23: Financiamiento de la investigación.}

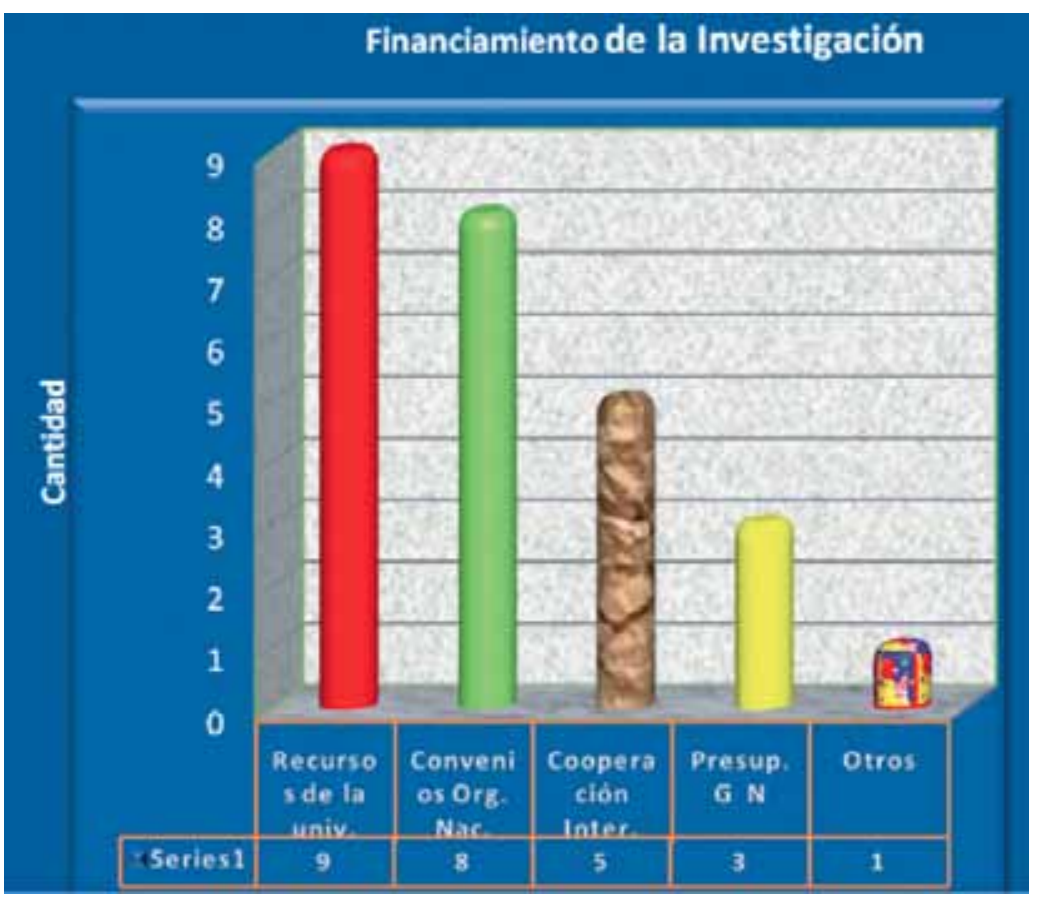

En relación al financiamiento, resalta que la totalidad de las instituciones estudiadas sostiene con fondos propios las investigaciones, como muestra el Gráfico $\mathrm{N}^{\circ} 23$. 


\section{UNIBE \\ Gráfico $\mathrm{N}^{\circ}$ 24: Modalidad para definir las investigaciones.}

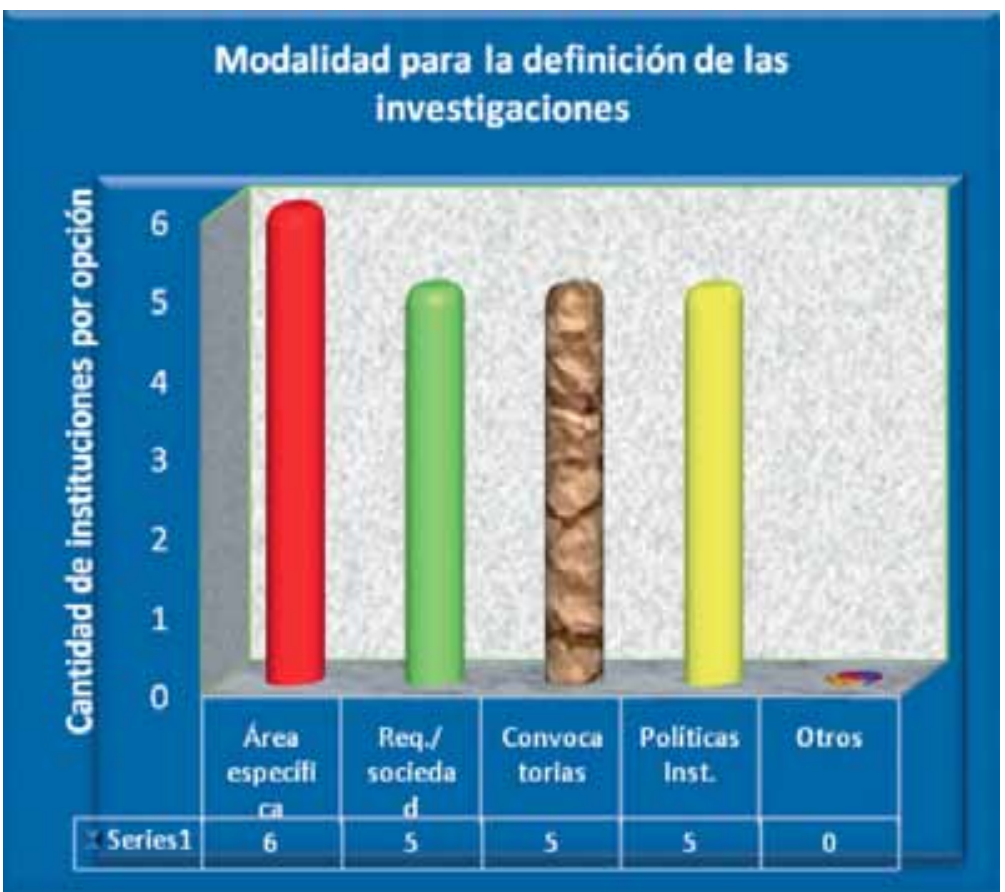

En cuanto a la modalidad para definir las investigaciones, se visualiza en el Gráfico $\mathrm{N}^{\circ} 28$ que varían entre: áreas específicas, requerimiento de la sociedad, convocatorias y líneas de política institucional. 
Gráfico N²5: Experiencias exitosas de Extensión.

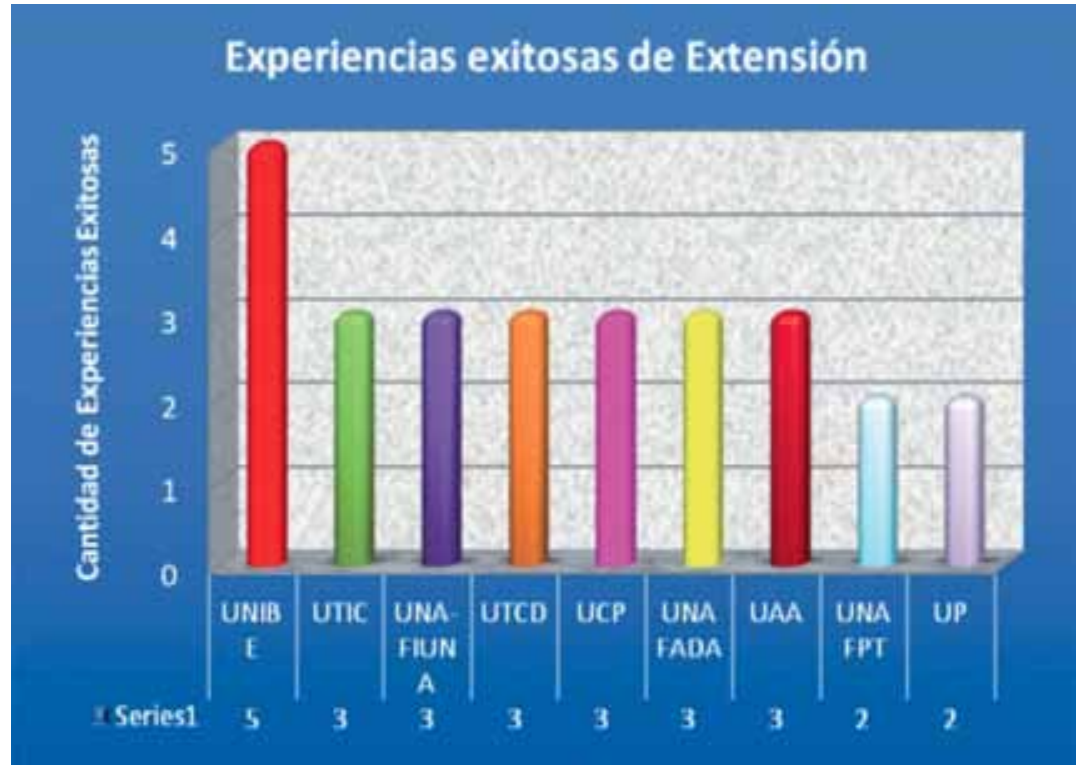

Los datos del Gráfico $\mathrm{N}^{\circ} 25$, muestran que los Centros estudiados identifican como exitosas una cantidad semejante de experiencias exitosas de extensión. 
DATOS REFERENTES A EXTENSIÓN E INNOVACIÓN N ${ }^{\circ} 26$ A 32

Gráfico $\mathbf{N}^{\circ}$ 26: Organización de las experiencias de extensión.

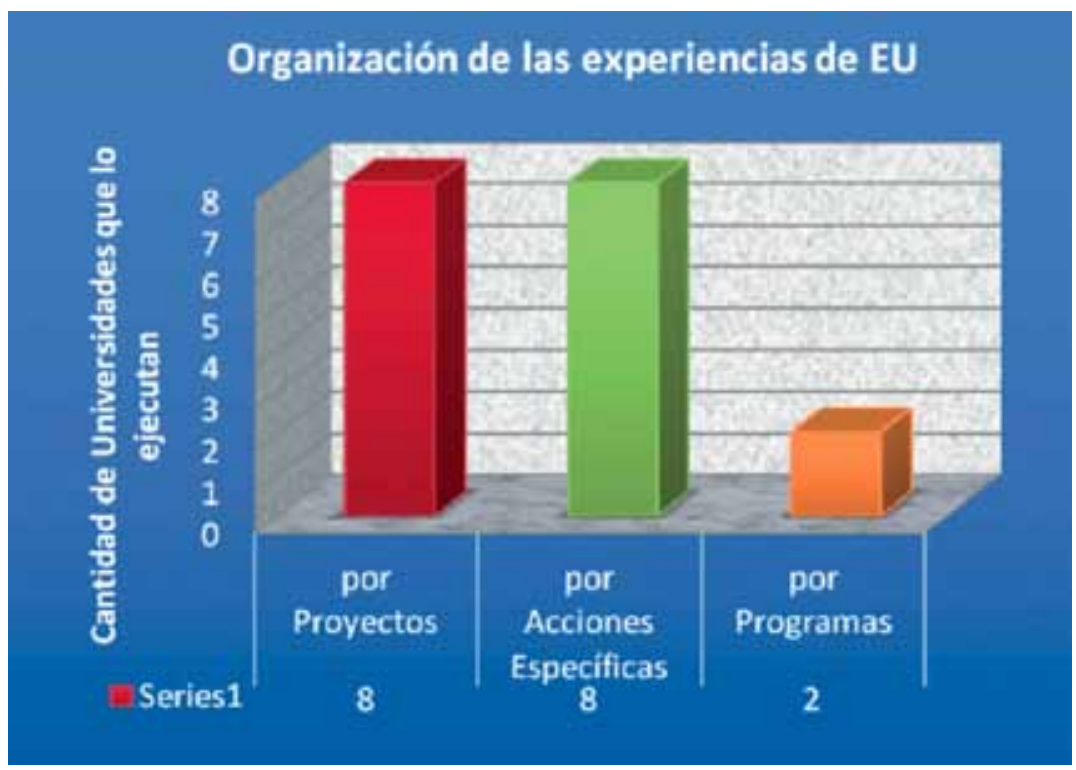

El Gráfico $\mathrm{N}^{\circ} 26$ indica que dichas actividades se organizan en su mayoría en Proyectos y Acciones específicas, lo cual evidencia que las acciones son puntuales y emergentes desconociéndose su sostenibilidad o la existencia de líneas que orientan las mismas. Lo dicho se refuerza con que sólo dos de las Instituciones declararon tener Programas de Extensión. 


\section{Gráfico $\mathbf{N}^{\circ}$ 27: Criterios para definir las acciones de extensión}

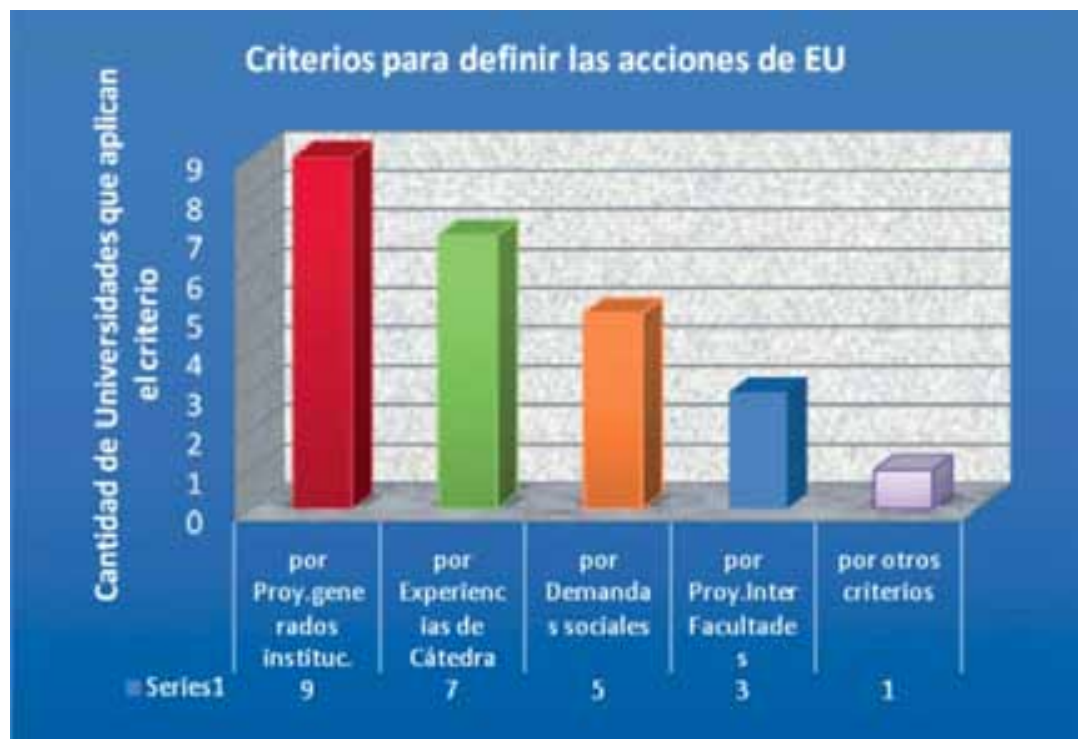

ElGráfico $\mathrm{N}^{\circ} 27$ muestraquelas Universidades definen predominantemente sus acciones de Extensión por Proyectos generados en las Instituciones y por decisiones de los profesores según sus experiencias de cátedra. 


\section{Gráfico $\mathbf{N}^{\circ}$ 28: Modos de financiamiento de la extensión.}

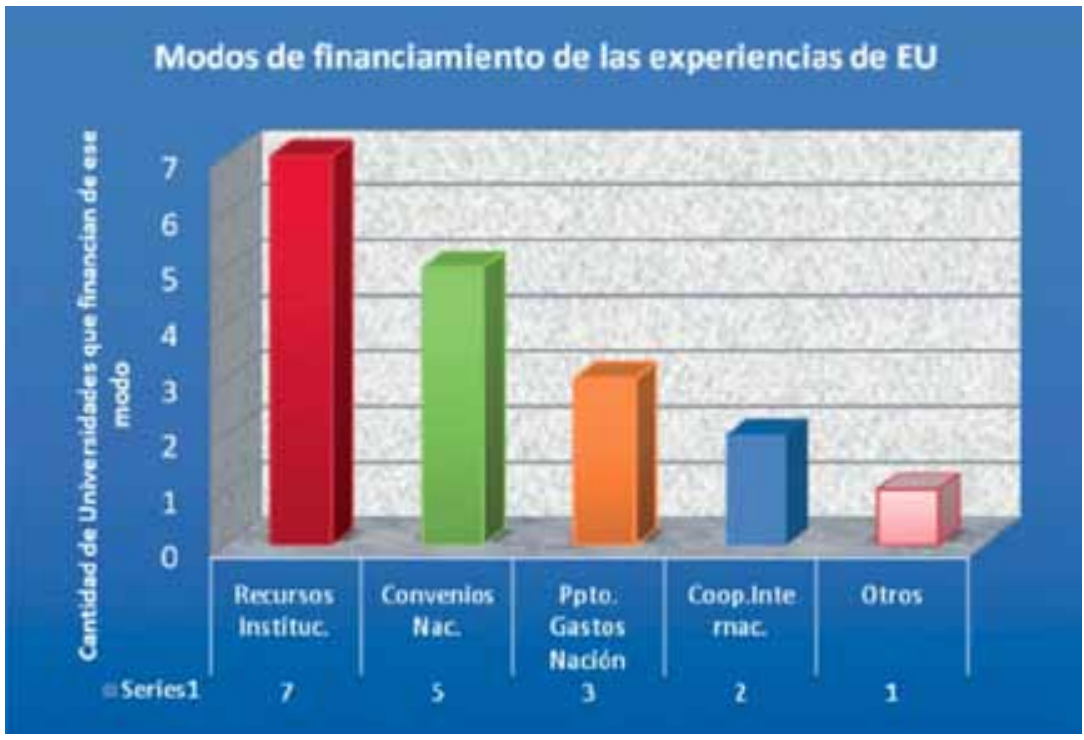

Los hallazgos del Gráfico $\mathrm{N}^{\circ} 28$, refuerzan el esfuerzo de las Universidades por asignar recursos institucionales para desarrollar los proyectos y acciones de Extensión, aunque no se averiguaron porcentajes las respuestas evidencian que se le presta atención. 
Gráfico $\mathbf{N}^{\circ}$ 29: Instancias de gestión de las experiencias de extensión.

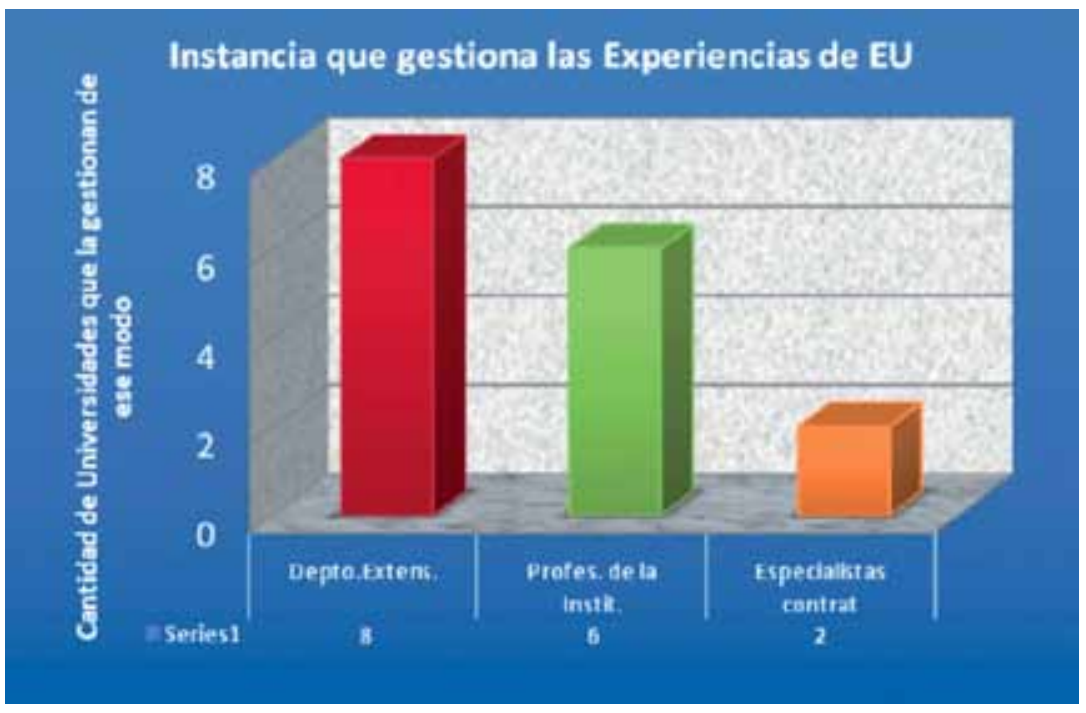

En cuanto a la instancia institucional por medio de la cual se gestionan las acciones prevalece el Departamento de Extensión tal como indica el Gráfico $N^{\circ} 29$; sin embargo se halla que seis de las Instituciones refieren gestionarlas también por medio de los profesores. 


\section{UNIBE

Gráfico N 30: Ámbitos en que se evidencia la innovación.

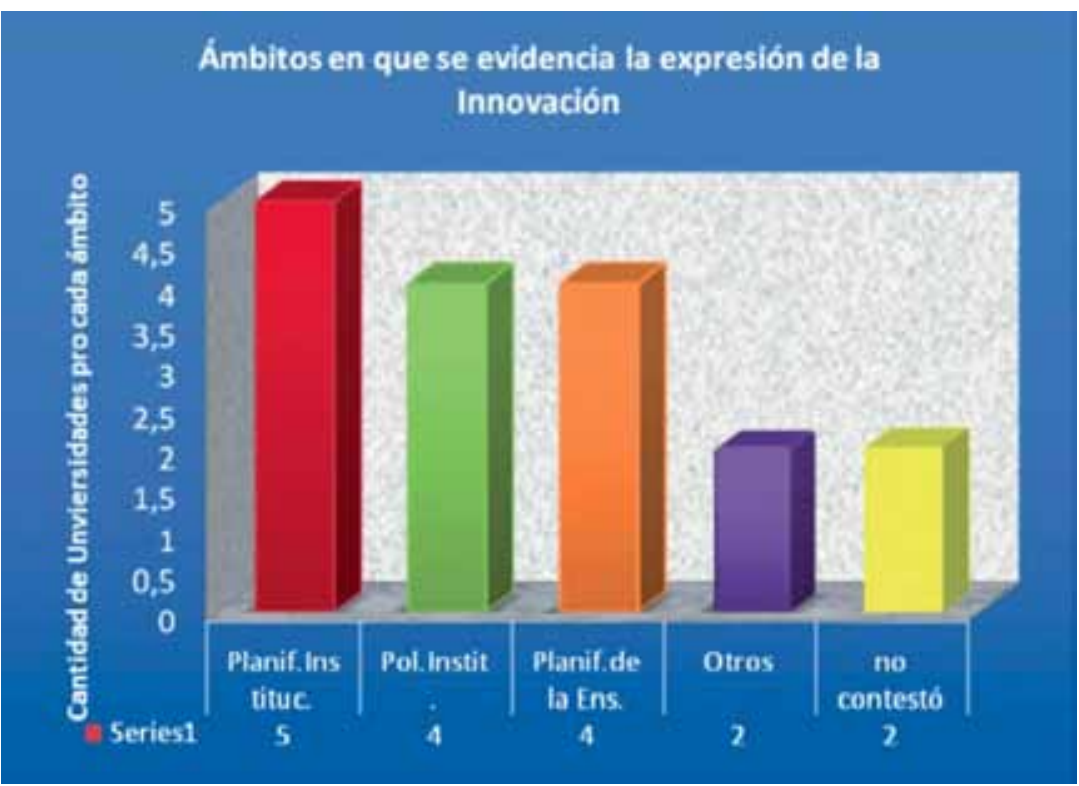

En el Gráfico $\mathrm{N}^{\circ}$ 30, los datos revelan que las Universidades explicitan la Innovación en mayor cantidad en la planificación, las políticas y la planificación de la enseñanza. Esto indica que si bien hay una innovación planificada con líneas institucionales también se observa que hay innovaciones bajo la iniciativa emergente o planificada de los catedráticos, aspecto éste que puede o no responder a las definiciones institucionales. 


\section{Gráfico $\mathbf{N}^{\circ}$ 31: Focalización de las experiencias de innovación.}

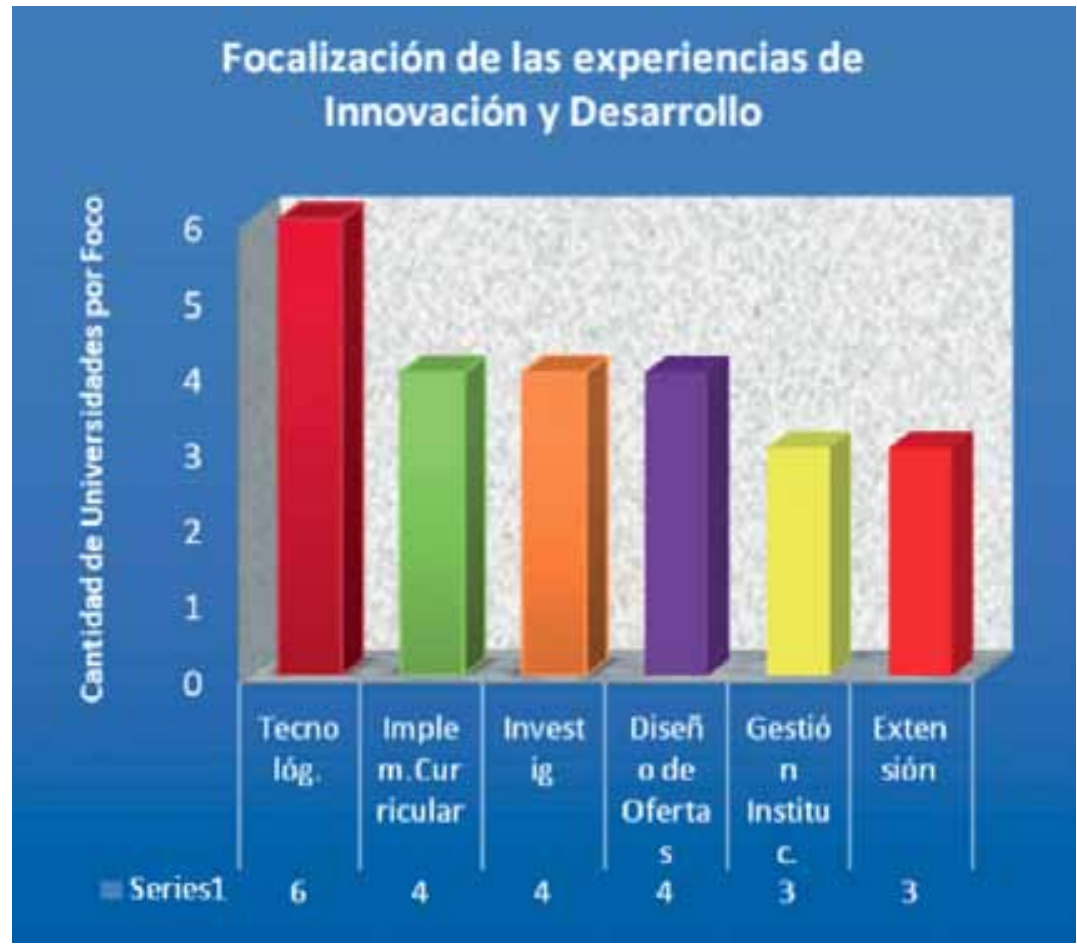

El Gráfico $\mathrm{N}^{\circ} 31$, muestra la tendencia de la innovación en el área Tecnológica, lo cual puede estar relacionado con el auge de la misma en esta época. No obstante también se nota que en el área curricular y la investigación existe un interés por incorporar innovaciones. 


\section{Gráfico No 32: Experiencias de innovación detectadas.}

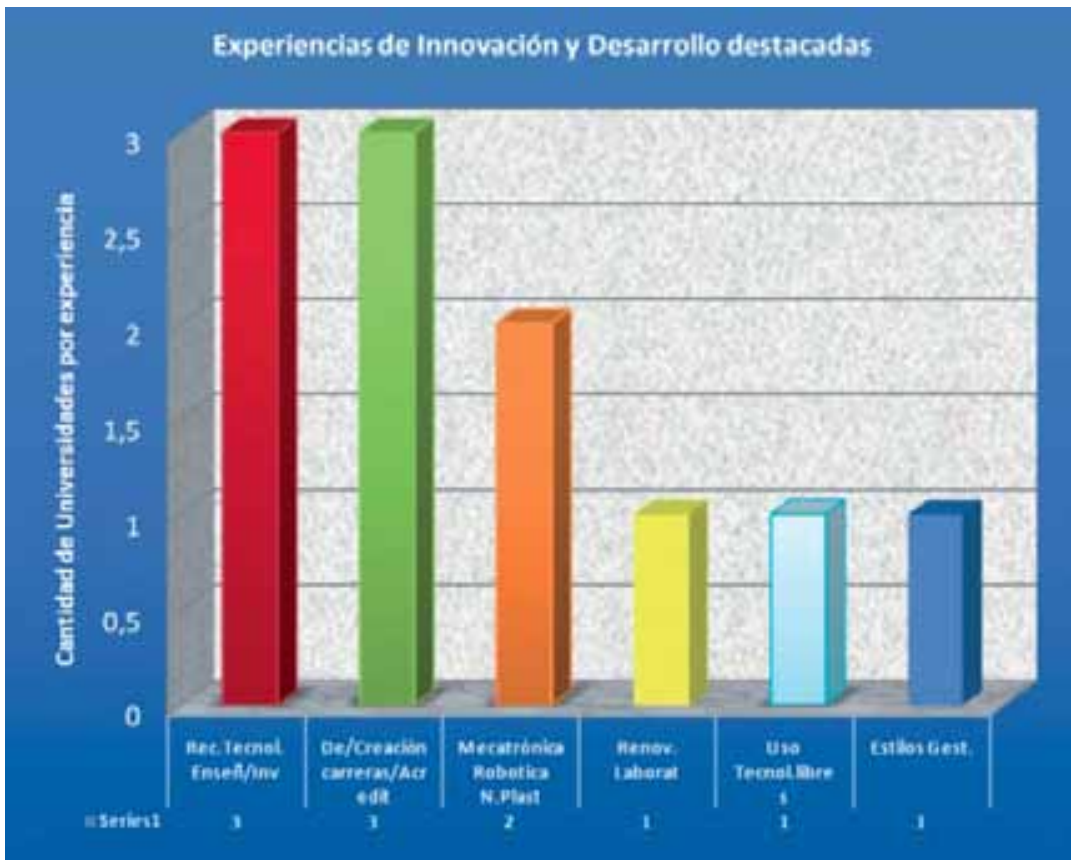

Según se observa en los hallazgos del Gráfico $\mathrm{N}^{\circ} 32$, las experiencias de innovación y desarrollo, más reconocidas por las Instituciones investigadas son las referentes a la utilización de la Tecnología como recurso para la enseñanza y el aprendizaje y la aplicación de la evaluación de carreras para la acreditación de las mismas.

Se mencionan también algunas innovaciones puntuales y llama la atención que sólo una institución reconoce innovar en los estilos de gestión, lo que concuerda con lo señalado en el Gráfico anterior. 
Datos Relacionados a la VinCUlaCión interinstitucional $\mathbf{N}^{0} 33$ a 37 Gráfico No 33: Prácticas de articulación con políticas macro.

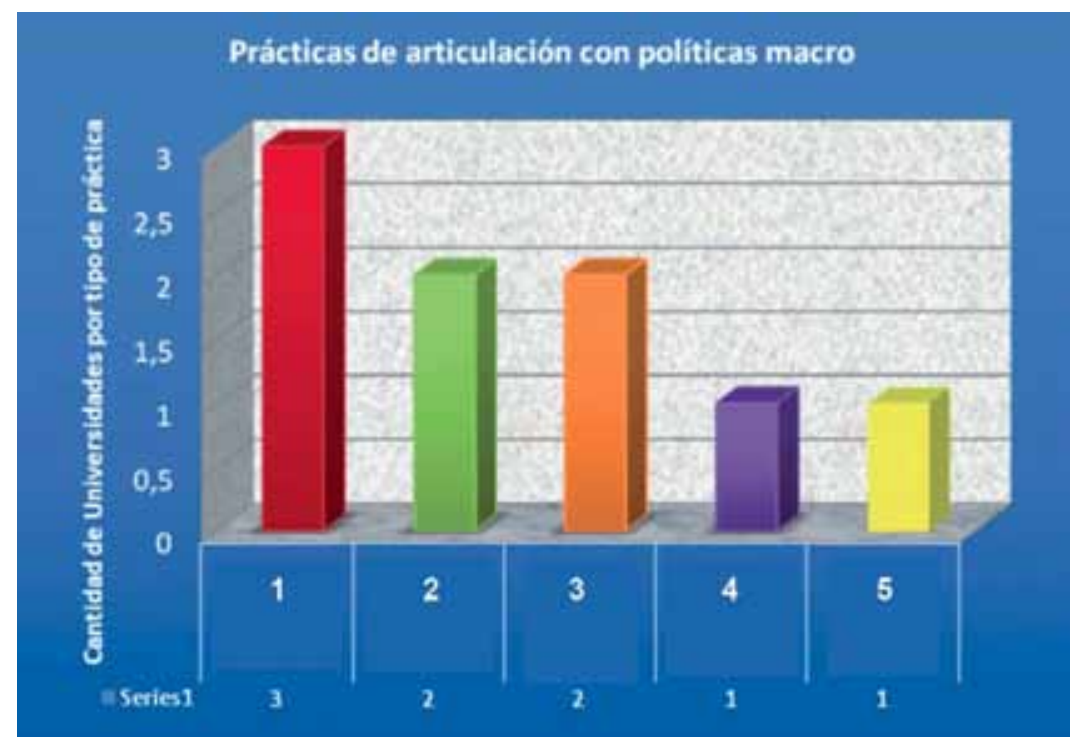

En el Gráfico $\mathrm{N}^{\circ} 33$ se visualiza la variación en las prácticas para articular las acciones institucionales con las políticas de la Educación Superior a nivel nacional, regional y mundial, mostrándose una leve tendencia hacia los convenios.

Entre las reconocidas, la movilidad estudiantil, si bien aparece en dos instituciones, es un medio de articulación con políticas internacionales. 
Gráfico $\mathbf{N}^{\circ}$ 34: Instituciones con las que se vinculan las universidades.

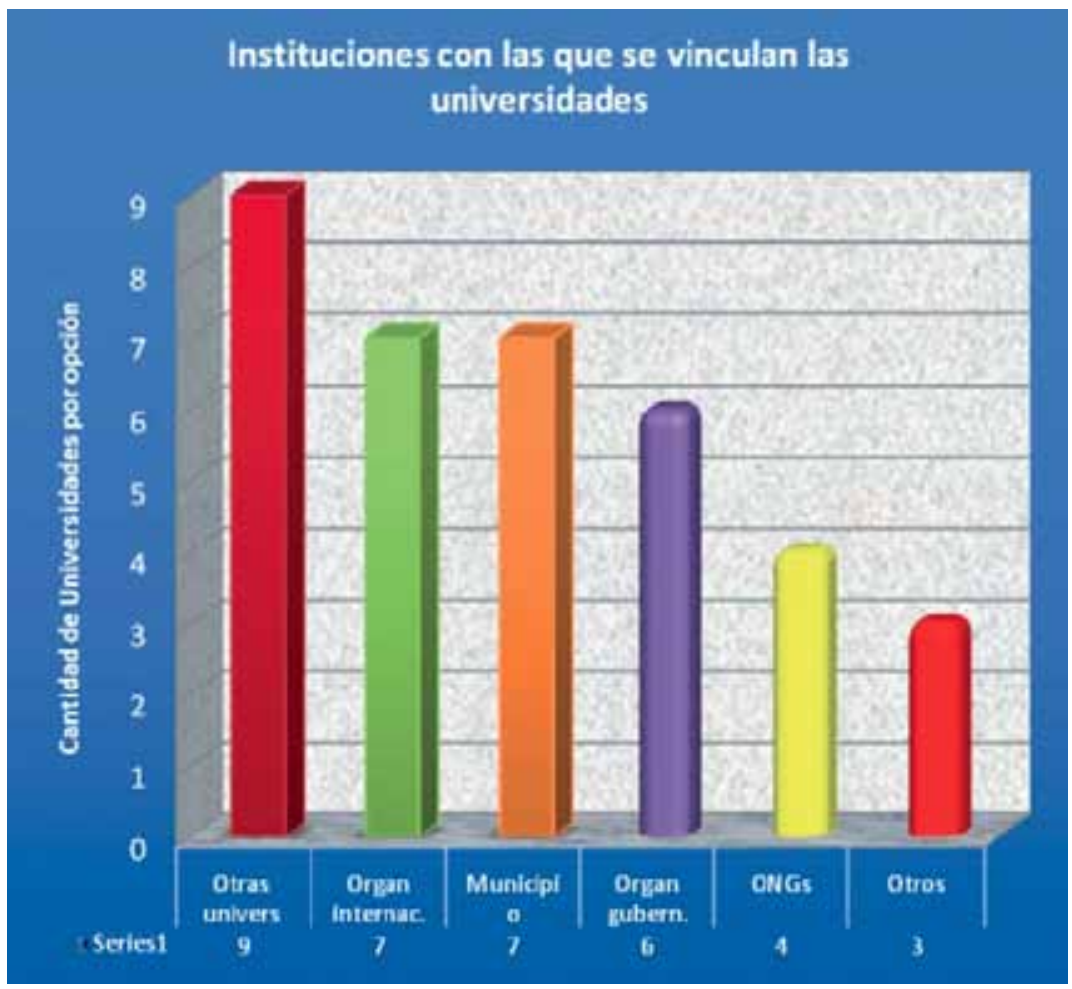

Los datos del Gráfico $\mathrm{N}^{\circ} 34$ revelan que las Universidades mantienen vínculos con sus pares y con organismos internacionales y nacionales. Esto manifiesta una apertura hacia el intercambio y la cooperación con otras instituciones, posibilitando la inserción en el ámbito internacional y el posicionamiento institucional. 


\section{Gráfico $\mathbf{N}^{0}$ 35: Acciones que promueven por la vinculación.}

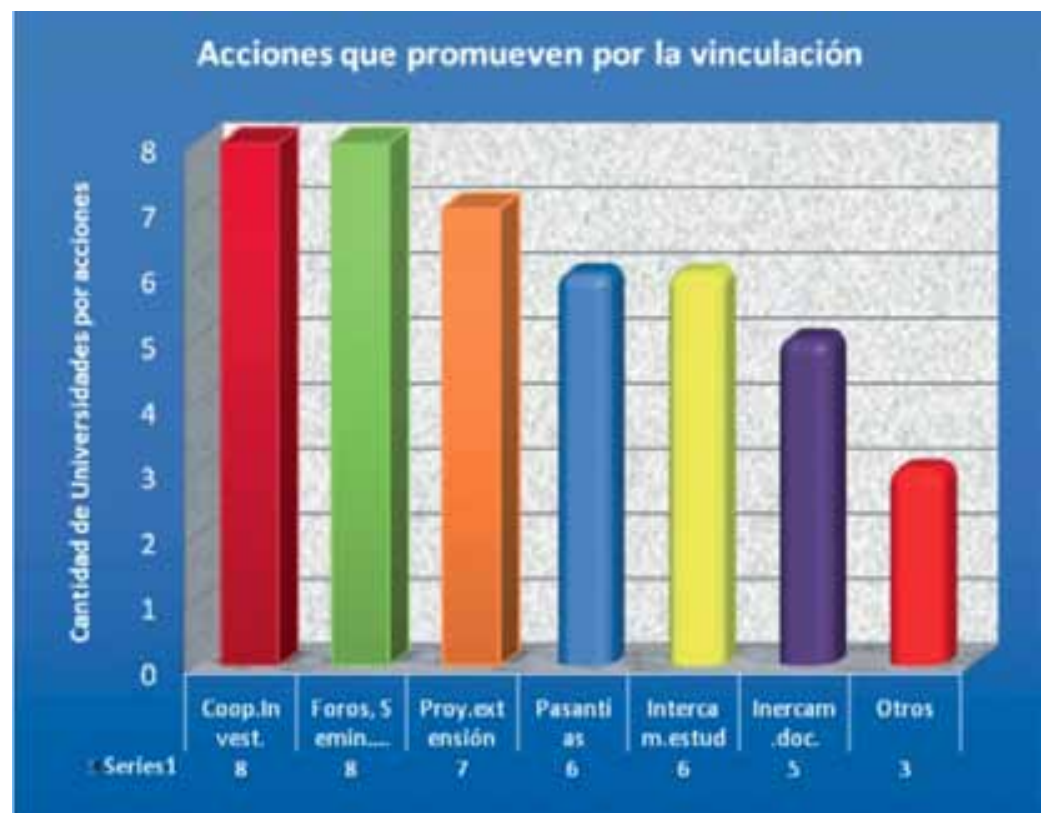

En relación a las acciones promovidas por dicha vinculación con otros organismos e instituciones, resalta en el Gráfico $\mathrm{N}^{\circ} 35$, la cooperación para el desarrollo de investigaciones y la realización de eventos académicos.

Se hace notorias las acciones como proyectos de extensión, pasantías e intercambios académicos de alumnos y en menor grado de docentes. 
Gráfico No 36: Participación en redes.

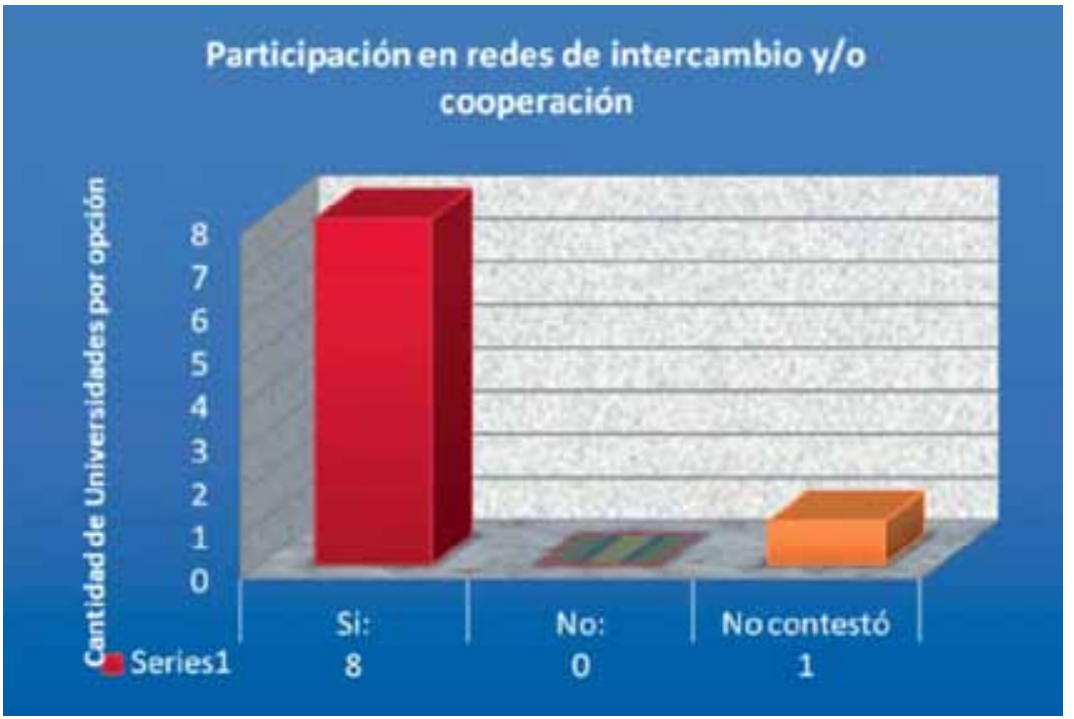

Resalta en los datos del Gráfico $\mathrm{N}^{\circ} 40$ que la participación en redes de intercambio o cooperación, es reconocida como práctica en ocho de las nueve instituciones investigadas.

Llama la atención que esta importante innovación no ha sido referida como tal en las experiencias reconocidas como innovadoras por las instituciones (Gráfico No 36 ). 
Gráfico No 37: Acciones que evidencian relación universidad-empresa.

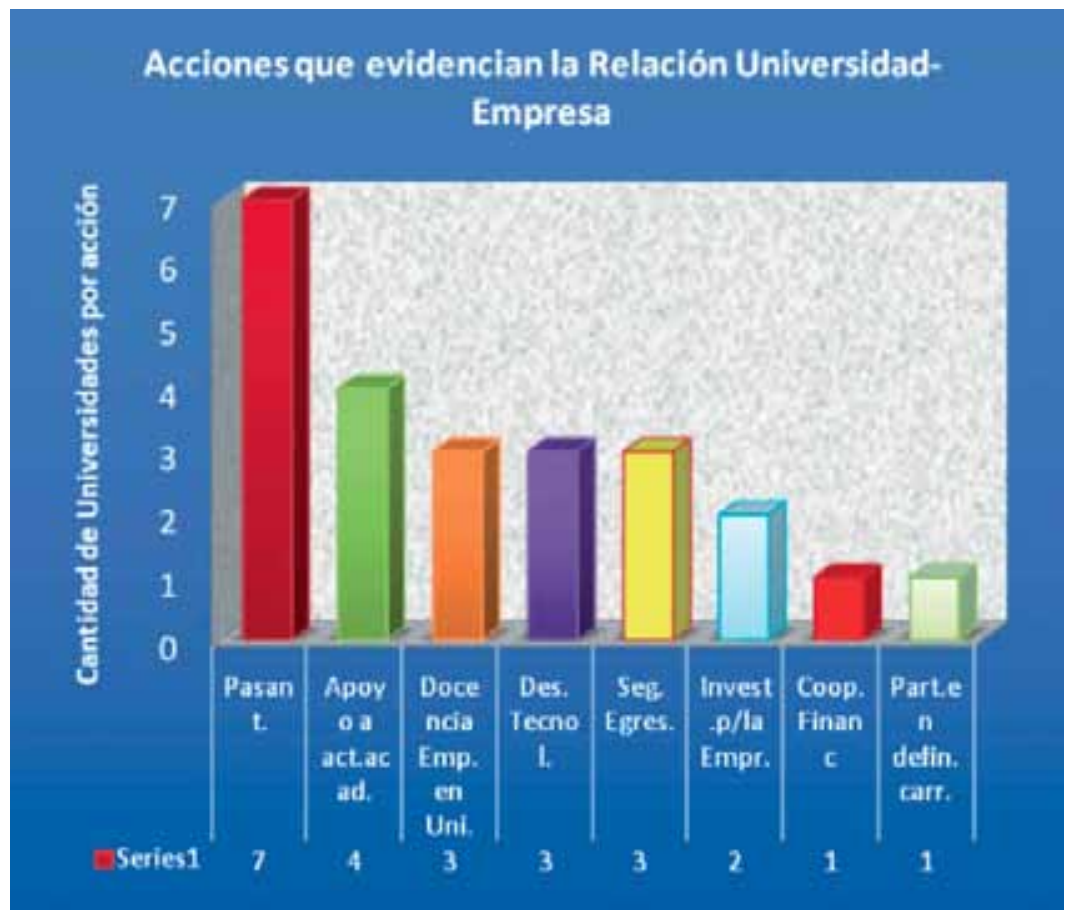

En la vinculación Universidad y Empresa, se destaca en el Gráfico $\mathrm{N}^{\circ} 41$ que la Pasantía sigue siendo la práctica más ejercida por las instituciones.

Si bien se mencionan otras acciones, son variadas y un aspecto llamativo es que sólo una institución mencionó como forma de relación la cooperación financiera y la participación de la empresa en la definición de las ofertas académicas. 
Datos SOBRe Financiamiento $N^{\circ} 38$ a 41

Gráfico $\mathrm{N}^{0}$ 38: Fuentes de financiamiento de las universidades.

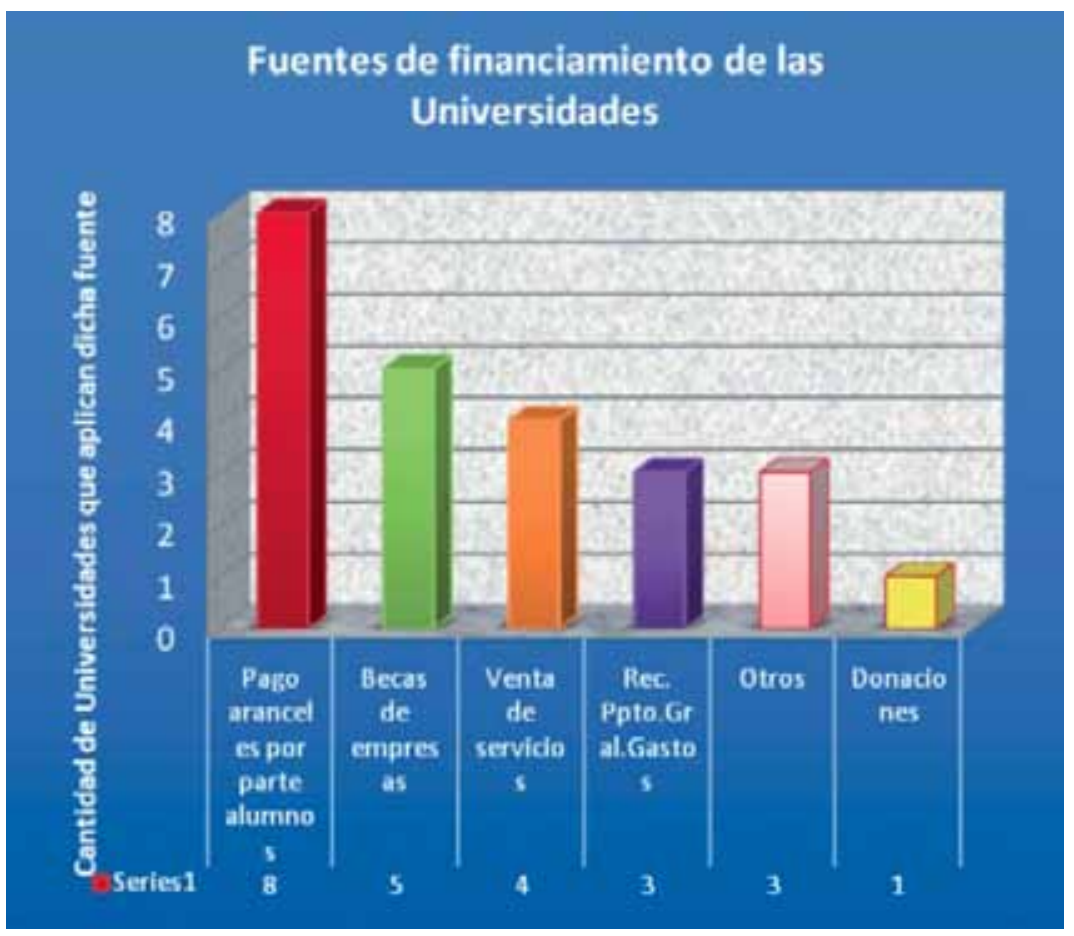

El Gráfico $\mathrm{N}^{\circ} 38$ muestra que la principal fuente de financiamiento de las instituciones, es el pago de las cuotas y aranceles por parte de los alumnos. Esto se relaciona con que la mayor cantidad de instituciones estudiadas es de gestión privada. Si bien las tres instituciones de gestión estatal reciben los recursos del presupuesto general de la Nación, también mencionaron que disponen otra fuente de ingresos que corresponde a pago de aranceles en diferentes conceptos por parte de los alumnos. Es importante, asimismo, el número de instituciones que reciben financiamiento en concepto de Becas a los estudiantes. 


\section{Gráfico $\mathbf{N}^{\circ}$ 39: Distribución presupuestaria de rubros}

relacionados a lo académico.

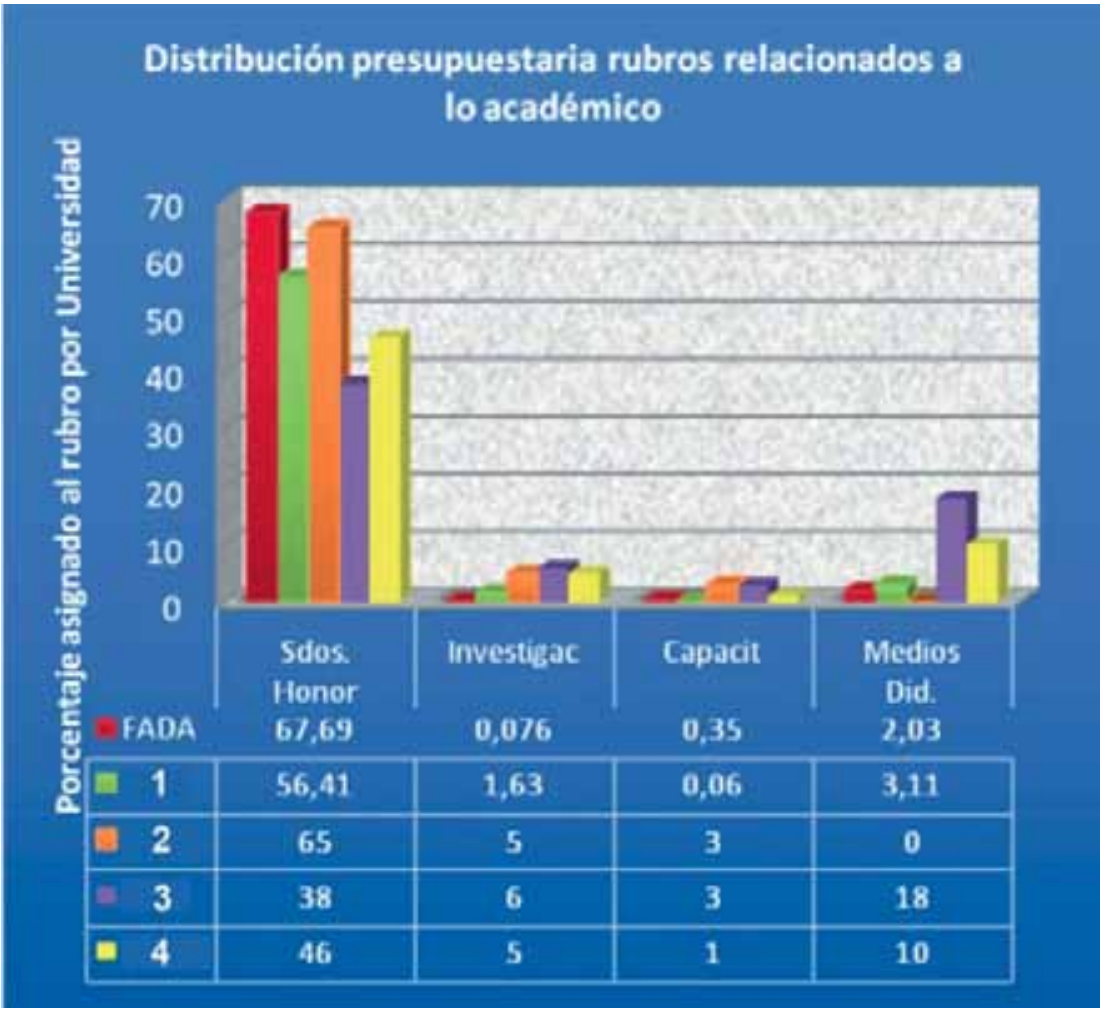

En el Gráfico N ${ }^{\circ} 39$ es notorio que los Sueldos y Honorarios concentran el mayor porcentaje en la distribución presupuestaria institucional. 


\section{Gráfico $\mathbf{N}^{\circ}$ 40: Distribución presupuestaria: rubros de} infraestructura y finanzas.

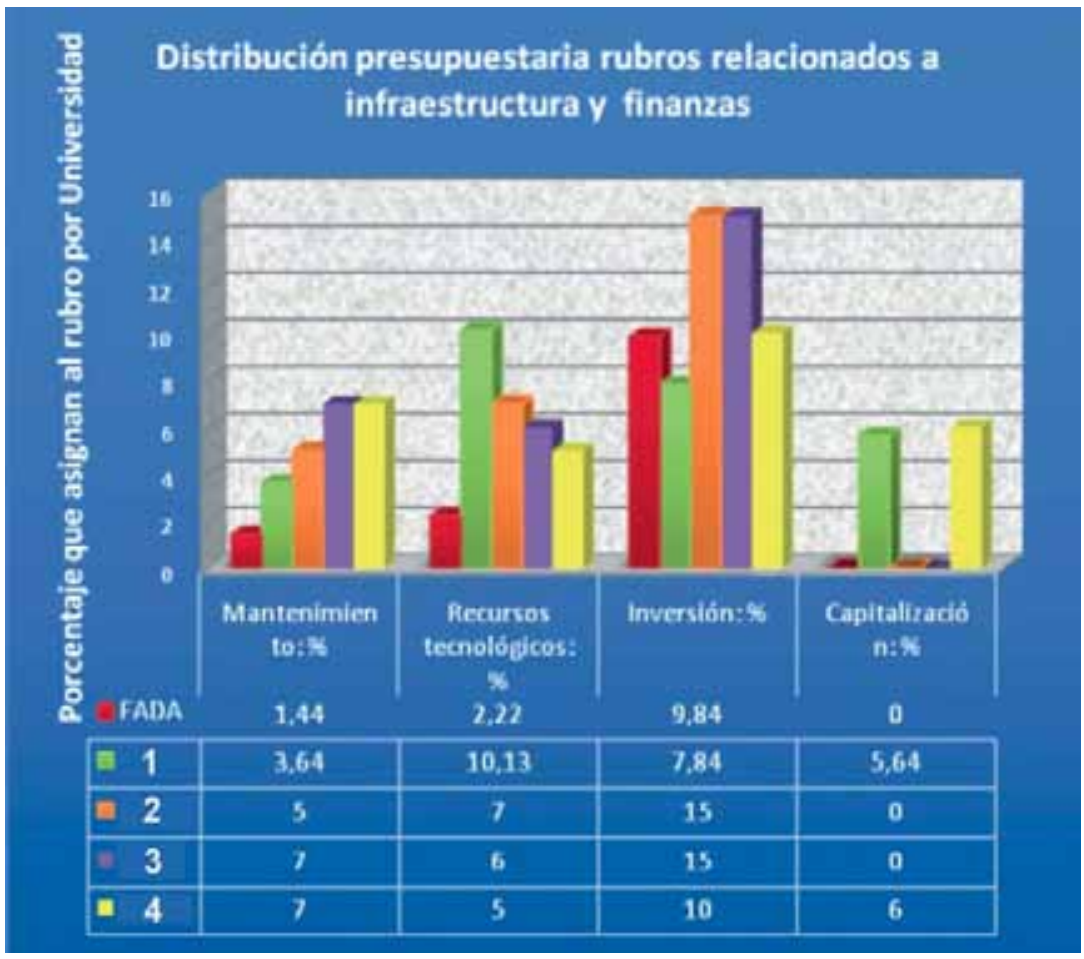

En la distribución presupuestaria, que muestra el Gráfico $\mathrm{N}^{\circ} 40$, la Inversión y los Recursos tecnológicos constituyen los rubros de mayor porcentaje.

El rubro mantenimiento sigue en orden de importancia, según el porcentaje asignado. 


\section{Gráfico $N^{\circ}$ 41: Promedio del costo de las cuotas.}

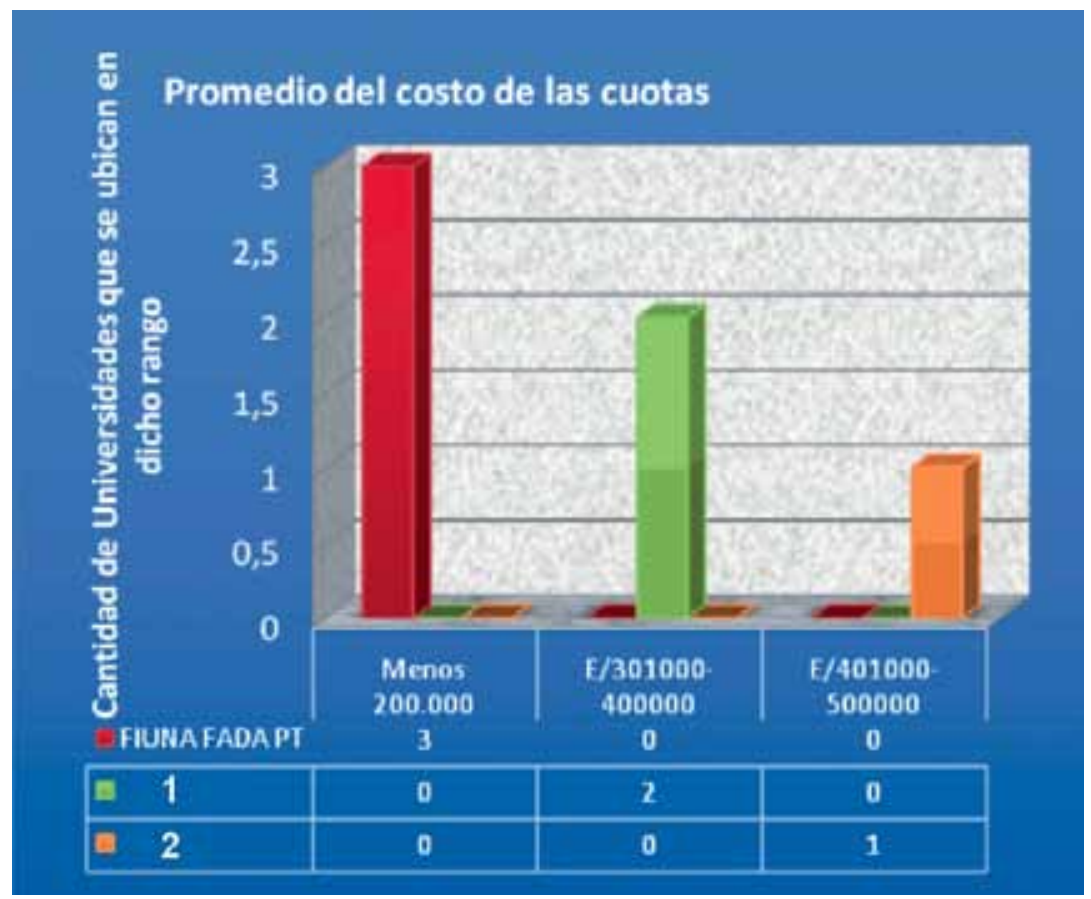

El Gráfico $\mathrm{N}^{\circ} 41$ revela en esta categoría, que las instituciones del sector estatal tienen aranceles más bajos que los de gestión privada. Esto se explica pues reciben rubros del Presupuesto General de la Nación. Las de gestión privada, no respondieron en su totalidad y de las tres que lo hicieron, dos perciben cuotas entre 301.000 y 400.000 guaraníes y una cobra cuotas superiores a estos montos. 


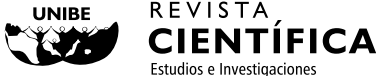

\section{DISCUSIÓN FINAL}

\subsection{Caracterización de las Universidades:}

\section{A. ORIGEN Y TIPO DE GESTIÓN}

Las Universidades estudiadas son instituciones con un promedio de quince años de historia, que si bien indica una trayectoria ya iniciada, en realidad si se mira la vida organizacional, son instituciones "jóvenes" en proceso de consolidación y desarrollo. Las mismas son de gestión privada.

Si bien estas instituciones fueron creadas en el período posterior a 1989, cabe aclarar que no forman parte de la explosión de nuevas universidades ocurrida a partir del 2005.

En contrapartida, de las tres Facultades estudiadas, comparten una historia centenaria, y con ella la estructura, la imagen, el prestigio, la cultura, el posicionamiento y la tradición.

Este crecimiento del número de instituciones universitarias se relaciona con la tendencia reafirmada por la UNESCO (1998) hacia la democratización de la matrícula universitaria y aumento del número de Instituciones con ofertas de Educación Superior. Si bien la expansión conllevó el riesgo del debilitamiento de la calidad, constituye una oportunidad para que mayor cantidad de ciudadanos se beneficien con los estudios universitarios.

\section{B. Organización}

En cuanto a la estructura organizacional, la totalidad cuenta con Jefaturas de Departamento, lo que indica la departamentalización en cuanto a las funciones. Asimismo la existencia de Direcciones de Carrera y Coordinaciones de carrera refiere a la concentración de la gestión en la implementación de las ofertas. Lo que se confirma en las instancias de gestión (gráfico $\mathrm{N}^{\circ} 3$ ) donde la totalidad prioriza la gestión por carreras. Esta importancia conferida al desarrollo de las carreras, no sólo es loable sino totalmente comprensible por la demanda y por ser el semillero de la captación de alumnos. Pero esta misma realidad puede significar el riesgo de la desarticulación de la gestión y del funcionamiento desde estancos.

En términos generales esta estructura tan similar en las instituciones, responde a las líneas establecidas para la organización por la Ley $\mathrm{N}^{\circ}$ 136/93 "de Universidades". Cabe señalar que si bien la organización de 
las universidades responde a la Ley, en la teoría de la gestión educativa, este modelo ha sido discutido y reformulado en sus principios.

$\mathrm{Al}$ respecto, en la misma cantidad, las instituciones declaran que cuentan con Decanatos lo que supone la existencia de Facultades por lo que puede inferirse que siete de las mismas, agrupan sus carreras por área de conocimiento aunque no queda claro si también la gestión.

Con referencia a los académicos (profesionales de la enseñanza universitaria) las instituciones, al seleccionarlos por antecedentes y contratación directa en su mayoría tienen por un lado, la posibilidad de una selección libre de presiones y acorde al justo criterio y por otro, el desafío a no caer en la subjetividad que afecta a la equidad

o en sistemas de exclusión -sobre todo las de gestión privada-. Este riesgo puede ser minimizado con el establecimiento de una carrera y de normativas legales que establezcan los procedimientos de ingreso y permanencia

Es de mencionar también que si bien cinco instituciones refieren que aplican sistema de incentivos, no especifican cuáles ni cómo lo implementan, lo que impide analizar en qué medida palia o no -al menos parcialmente- la situación.

Cabe destacar que siendo el tema financiero tan sensible, no todas las instituciones respondieron al mismo.

Otro aspecto coincidente en las instituciones es que todas regulan su funcionamiento por medio de Estatutos y Reglamentos específicos, lo cual es una evidencia de la autonomía universitaria consagrada y definida en el marco legislativo nacional y por la comunidad universitaria mundial.

\section{INFRAESTRUCTURA y EQUiPAMIENTO}

Resulta interesante que la totalidad de las instituciones investigadas, cuentan con espacios pedagógicos básicos y acceso a bibliotecas virtuales; este último recurso posiciona a las nueve instituciones en el mundo de las nuevas tecnologías al servicio de la educación universitaria. Pero este dato no fue reconocido - paradójicamente- entre las innovaciones declaradas en la dimensión correspondiente "Gestión de la Innovación". Esto podría significar que dicha facilidad o no está suficientemente instalada como recurso o no es tenida aún en cuenta por el incipiente posicionamiento de la modalidad virtual en la educación. Este predominio de los servicios informáticos educativos, se reitera en la existencia de laboratorios de 
informática, salas con internet para alumnos en las nueve instituciones estudiadas y salas de internet para profesores en ocho de ellas. Con dichas facilidades tecnológicas los alumnos y profesores tienen a su disposición recursos de avance para el proceso de enseñanza aprendizaje, pero caben algunas preguntas como: ¿cuán disponibles están en el tiempo real dichos recursos para que puedan ser usados? No obstante la existencia, queda sin datos la accesibilidad a los mismos. En cuanto a los laboratorios especializados, es loable que algunas las carreras cuenten en estas instituciones con espacios específicos.

Es gratificante que las instituciones estudiadas, cuenten con un escenario físico adecuado para los cargos de gestión y de servicios básicos, lo cual propicia un clima de trabajo y de estudio favorable ya que el espacio físico otorgado es indicador de la importancia asignada a la tarea. Como ejemplo valga la existencia de accesos para personas con necesidades especiales lo que indica una clara implementación de la inclusión en la cotidianeidad de estas instituciones.

\subsection{IDENTIFICACIÓN DE LAS OFERTAS ACADÉMICAS}

\section{A. Grado}

La multiplicidad de especialidades en las ofertas de grado, nos permite discutir la pertinencia de las mismas en relación a la realidad social nacional y local. Es de señalar que un área de conocimiento tan fundamental en la economía paraguaya como lo es la agropecuaria, cuenta con sólo ocho carreras, sin embargo las del sector servicios ${ }^{2}$ agrupan a cuarenta y seis carreras.

En cuanto a las ofertas del área Tecnológica, que representan la mayor cantidad de carreras, indican una respuesta a las necesidades de la sociedad. Asimismo, llama la atención la multiplicidad de denominaciones adoptadas para carreras similares, cuyo objeto de estudio es el mismo. Esto podría afectar la movilidad estudiantil incluso entre las universidades del país, aún cuando la autonomía universitaria garantiza la libertad para generar ofertas. Este análisis nos remite a la necesidad de establecer políticas de formación basadas en diagnósticos sistematizados de la realidad nacional y regional, que den origen a las carreras para no basarse exclusivamente en la demanda de los usuarios. El Estado, en este caso podía peticionar a las instituciones que oferten cursos a fin de que los funcionarios públicos se capaciten.

2. Carreras de Administración, Contabilidad, Humanística y Jurídico Política. 


\section{B. Post Grado}

Resulta evidente un desarrollo en el nivel de los estudios de post grado, desde los diplomados pasando por las especializaciones y las maestrías hasta doctorados. Lo que se destaca es la articulación entre las ofertas mayoritarias de grado y las de las mismas áreas en el nivel de post grado, se van articulando a un ritmo lento.

Entre las especializaciones, la más ofrecida es la de Didáctica Universitaria, lo cual responde a una demanda planteada por el sector universitario para el ejercicio de la docencia por parte de los profesionales.

Respecto de las maestrías, las más numerosas son en Educación y en las Ingenierías. Se confirma que existe una tendencia de concentración de los post grados en el área educativa. Teniendo en cuenta que las maestrías lideran las ofertas de este nivel.

\subsection{EXPERIENCIAS de InvestigaCión, Extensión E InNOVACión}

\section{A. INVESTIGACIÓN}

Se nota que hay un esfuerzo de incorporar como ámbito de gestión universitaria a la investigación, por la existencia de los Departamentos del área y referencias a proyectos y algunos programas. Las experiencias referidas permiten señalar que el posicionamiento es aún débil.

Esto es congruente con la definición de las líneas de investigación que son diversas y las fuentes de financiamiento mayoritariamente provenientes de recursos de las universidades. Es de tomar en cuenta que seis de las estudiadas son de gestión privada, lo que acentúa la necesidad de generar alternativas para financiar la investigación entendida como inversión y no como gasto y esfuerzo insostenible.

\section{B. EXTENSIÓN}

Las experiencias de extensión reconocidas por las instituciones, si bien indican acciones al respecto, muestran por un lado una escasa cantidad en relación al cuantioso número de carreras existentes, y por otro la dispersión en cuanto al tipo de actividades pues los criterios se aproximan a lo situacional o emergente.

Si bien todas poseen una instancia de Extensión en la estructura organizacional, lo cual es favorable, no se visualizan líneas definidas que orienten las acciones de extensión. Esto lleva a plantearse la cuestión de 
en qué medida la extensión está instalada en el colectivo universitario como una actividad inherente a la Educación Universitaria.

\section{INNOVACIÓN}

La innovación se focaliza en lo tecnológico como recurso pedagógico, incorporando equipamiento para mejorar los servicios. Esto se refuerza en que la misma se gestiona en función de la planificación institucional por un lado, y por otro la planificación de la enseñanza. En cuanto al aspecto institucional, la innovación responde a inversiones para el avance en la prestación de los servicios y en lo referente a la enseñanza, se relaciona con nuevas formas de organización e implementación del acto pedagógico.

Hay experiencias resaltantes como la implementación de Mecatrónica y Robótica como asignaturas en el plan de estudio y la producción de nuevos plásticos como resultado de la investigación.

En cuanto a la gestión, exceptuando la evaluación y acreditación de carreras, las experiencias innovadoras van ganando terreno a un ritmo que quizás no coincida con el tiempo presente.

\subsection{VinculaCión y ArTiculaCión InTERINSTITUCIONAL}

Las prácticas de articulación con macropolíticas, formalizadas a través de convenios constituyen un indicio del incipiente proceso de internacionalización y de gestión cooperativa característico de este tiempo.

Esta vinculación se destaca en las relaciones desarrolladas con otras universidades y con organismos internacionales y nacionales lo cual favorece la inserción en el ámbito de la comunidad académica y posibilita la generación de redes. Merece especial mención la apertura que dicha práctica requiere y que en los casos estudiados, está en proceso.

De acuerdo con las áreas en torno a las cuales se concreta la vinculación, se presenta un panorama alentador para promover investigaciones y foros o congresos entre varias instituciones lo cual aúna y economiza esfuerzos y recursos a la vez que optimiza la calidad de las acciones y los resultados.

Específicamente en la relación con el sector empresarial, se evidencia mayoritariamente un solo tipo de lazo dado a través de las pasantías de los estudiantes, práctica ya tradicional para este vínculo. Queda pendiente 
aún el desafío de integrar a la empresa en la discusión de la pertinencia y la respuesta de las ofertas que se generan desde las universidades.

\subsection{FinANCIAMIENTO}

El costo del financiamiento en las Universidades de gestión estatal, es solventado con recursos del Tesoro Nacional, asignados en el Presupuesto General de la Nación y en menor medida por el pago de aranceles varios abonados por los usuarios de los servicios. (Recursos propios de Fuente 30)

Esto nos muestra que la gratuidad de los estudios universitarios en nuestro país, no es tal puesto que requiere del cursante un mínimo de recursos para hacer frente a los aranceles establecidos -que si bien generalmente vuelven en servicios- el alumno debe disponerlos para no cortar su proceso.

En el caso de las universidades privadas, que en esta investigación son mayoría, la principal fuente de financiamiento proviene del cobro de las cuotas y aranceles a los alumnos. Lo que puede verse en términos de distribución es que la mayor proporción de los recursos que ingresan, se destina al pago de los honorarios al personal lo que deja sin duda poco margen a los otros rubros tales como investigación, extensión, inversiones en equipamiento e infraestructura, planes de desarrollo de los profesionales, y otros.

Esta situación es limitante teniendo en cuenta los requerimientos de una Educación Superior de calidad. Calidad-Costo-Cobertura, al decir de Rama (2006) constituyen las aristas de un triángulo de equilibrio inestable pues la modificación en una de ellas incide en las otras. Resulta claro que la Calidad tiene su costo y que las instituciones universitarias requieren gestionar nuevas fuentes de financiamiento para el desarrollo de las ofertas, caso contrario se afectará

o la Cobertura o la Calidad. Aquí se evidencia la necesidad del apoyo decidido del Estado para con las universidades de gestión privada. Por medio de becas, incentivos, cursos y estrategias varias, se podría fortalecer a las mismas. Es uncuestionable, en ese sentido, el rol que cumple las universidades de gestión privada en relación al acceso a la educación que ofrecen a los ciudadanos a lo largo y ancho del país, es insoslayable. 


\section{CONCLUSIÓN}

El trabajo se basó en la información brindada por los referentes claves designados por las nueve instituciones estudiadas y los datos disponibles en la web sobre las mismas, por lo cual no tiene pretensión de generalización alguna.

La recolección de los datos, se realizó por medio de una encuesta a los actores en función de la disponibilidad de los mismos para acceder al estudio y del tiempo real definido. Esto restringe la profundización de los hallazgos pues se basa en la percepción de un segmento de los involucrados en la gestión de las universidades.

Resalta que pese a la cantidad de instituciones invitadas, sólo accedieron a participar nueve de ellas y lo hicieron con apertura, buena disposición e interés por la experiencia.

Se rescata el empeño evidenciado por las instituciones para desarrollar la investigación, la extensión, la innovación y por sobre todo la formación profesional. Asimismo las oportunidades que generan con las ofertas constituyen un aspecto digno de mención que refiere a la búsqueda constante de respuestas a la sociedad.

Los hallazgos de la investigación permiten concluir que si bien la mayoría de las instituciones universitarias fueron creadas en el contexto de la apertura democrática del Paraguay, post 1989, es decir no son de reciente aparición y se encuentran en el proceso de fortalecimiento y posicionamiento institucional. Este proceso se está desarrollando en plena expansión de los estudios superiores, en coincidencia con las tendencias señaladas por la UNESCO (2009) y Rama (2006).

Por la estructura institucional declarada, organización por facultades, por carreras, por departamentos, ubica a las instituciones en una práctica fragmentada que dificulta la visión integrada de la gestión, en discordancia con los nuevos modelos de gestión que plantean una óptica de totalidad articulada en torno a los tres ejes de acción: investigación e innovación, extensión y enseñanza o formación profesional. Esta situación lleva a reflexionar sobre la pertinencia de este modelo de gestión así como la necesidad de una definición de políticas que se traduzcan en objetivos, estrategias y actividades integradoras. En pos de una economía de los esfuerzos y recursos y de una mayor eficacia en los resultados e impacto sería oportuno generar programas institucionales e interinstitucionales de investigación, extensión e 
innovación en los que cada unidad operativa participe desde su área o especialidad, garantizando la sostenibilidad de los mismos.

En relación a la organización de los académicos, el modo de contratación obedece a la dinámica de la gestión de las universidades privadas. Se sugiere que el Estado apoye por medio de incentivos y programas para el efecto.

Con respecto a la infraestructura edilicia, se concluye que las instituciones investigadas cuentan con la infraestructura y el equipamiento básico necesario para su funcionamiento. Cabe destacar que se percibe el esfuerzo de todas ellas por dotar de equipamiento tecnológico que facilite el desarrollo de la enseñanza aprendizaje. No obstante sería necesario llegar a que todos puedan acceder a dichos medios lo que desafía a la gestión de las instituciones.

Este aspecto de la infraestructura es relevante pues es un indicador del lugar que se le asigna en la realidad institucional a cada función y por tanto la importancia conferida a los cargos y constituye una evidencia de la veracidad en la implementación del organigrama.

En el eje formación profesional, predominan las carreras de grado como ofertas múltiples y con diversidad de denominación. No se obtuvo la certeza de la existencia de un diagnóstico sistemático para dar origen a las carreras ni líneas estratégicas que respondan a políticas de formación. Un caso que merece atención constituye la poca cantidad de ofertas para el sector agropecuario, siendo éste clave para el desarrollo nacional. Puede explicarse esta predominancia por ser las carreras de grado la base de sostenibilidad económica de las instituciones universitarias. Asimismo, la creciente demanda de los usuarios amplió significativamente el número de ofertas de grado pero tal vez sin responder a los requerimientos del ámbito socio productivo nacional. Si bien esto favorece la democratización de los estudios universitarios, llama una vez más a la reflexión sobre el triángulo Costo-Calidad-Cobertura.

En cuanto al nivel de Post Grado, el área de educación es una de las más ofertadas tanto en Maestría como en Diplomados y Especializaciones. Se plantea la necesidad de indagar acerca del impacto de la formación de Post Grado, en uno de sus aspectos fundamentales como es la investigación.

Respecto del eje Investigación, así como Innovación y Extensión, estamos ante un incipiente desarrollo con evidentes esfuerzos para promoverlos a partir de diferentes iniciativas y experiencias. Aunque esto no indica 
que la cultura investigativa se haya posicionado en las instituciones. La existencia de un Departamento de Investigación, supone que la institución otorga importancia a la misma y por ello le abre el espacio y la jerarquiza. Es loable que a pesar de las dificultades en los recursos, se mantenga en la estructura. Sería importante que Docencia e investigación se vinculen de manera más efectiva en la promoción y el desarrollo de la investigación; la contratación de especialistas externos podría tener como consecuencia una escasa instalación de la cultura investigativa en la institución y daría un mensaje de escisión entre docencia e investigación, mirada contraria o desfasada a la línea promovida por Unesco y otras tendencias señaladas por diferentes autores.

En cuanto a la innovación, la situación no varía e incluso presenta una falta de reconocimiento de las innovaciones realizadas, lo que puede deberse a que no está institucionalizado el tema en cuestión y se realiza en forma emergente y desarticulada. Lo mismo puede concluirse para la Extensión, ante la carencia de Programas definidos institucionalmente lo que pone en riesgo la sostenibilidad y el posicionamiento de estos ejes tanto por ser la Investigación y la Extensión fines propios de la Educación Superior, como por ser la Innovación un eje global necesario en la gestión institucional.

La vinculación interinstitucional se focaliza en convenios con distintas organizaciones que apuntan a acciones cooperativas y en pasantías fundamentalmente de estudiantes desarrolladas como práctica profesional. Los convenios generan redes en las cuales, el profesorado está integrado en forma elemental. La vinculación con las empresas tiene pendiente la discusión de ofertas, nuevas formas de financiamiento y participación en la formación como nuevas formas de relación e integración del sector.

En lo referente al financiamiento la mayor proporción del presupuesto que disponen las universidades tanto públicas como privadas, se destina a pago de sueldos, quedando poco margen para los otros fines, dicha situación desafía a las instituciones a buscar otras fuentes de financiamiento que permitan obtener recursos para el desarrollo de la investigación, de la extensión y de la innovación. Sería importante que la asignación presupuestaria en el caso de las instituciones de gestión estatal incorpore indicadores de eficiencia en el uso de los recursos de modo a mejorar las asignaciones a las instituciones con mejores resultados. Y en el caso de las instituciones de gestión privada, convendría una evaluación del impacto de las experiencias o de la eficiencia en el uso 
de los recursos asignados a cada sector, a fin de replicar o re-direccionar los mismos según los resultados.

El presente estudio, queda abierto como experiencia, a próximas investigaciones ya sea para extender a otras instituciones o profundizar en los hallazgos. El trabajo se plantea como un aporte para continuar la reflexión y el análisis de la Educación Superior, para lo cual se presentan algunas consideraciones a futuro.

\section{CONSIDERACIONES A FUTURo}

La gestión de las instituciones emerge como uno de los desafíos a fin de posibilitar el desarrollo armónico de los tres ejes de acción de las universidades: formación profesional, investigación y extensión. La generación de innovaciones ha de ser acompañada por una gestión innovadora pues sólo así se asegura la calidad y la sostenibilidad de los programas. Es necesario discutir los modelos de organización y gestión que se implementan de modo a superar la fragmentación de las acciones de las diferentes áreas y acordar políticas sistémicas que promuevan acciones sistematizadas. Asimismo, el establecimiento de estrategias institucionales que permitan visualizar la proyección, el impacto y la sostenibilidad de las acciones, contribuirá a un proceso de aseguramiento de la calidad.

- La organización de los académicos, requiere el apoyo del Estado a fin de ir consolidando este importante rol. Se considera importante la disponibilidad de tiempo y espacio para que los profesores interactúen y discutan ideas con sus pares, para realizar investigaciones, para producir publicaciones, para desarrollar las tutorías académicas como tarea propia de la enseñanza. Asimismo, los académicos construyendo su autoría de pensamiento, podrán transmitir sus saberes a los noveles docentes.

- Otro aspecto a considerar constituye la creación de un sistema que establezca la carrera del docente universitario. Esta carrera debe contemplar tanto el ingreso como el desarrollo profesional del docente y las estrategias de apoyo institucionales.

- La Educación Superior se enfrenta al reto de una caracterización sistemática y sistematizada del ámbito socio económico que fundamente la creación de carreras, en especial las de grado. Asimismo es necesario que las ofertas académicas, se articulen con las políticas de desarrollo nacional y regional. 
- La multiplicidad de ofertas semejantes en una misma área y con diferentes denominaciones, requiere la generación de una matriz de denominaciones equivalentes entre las carreras ofrecidas por las distintas instituciones, a fin de definir el campo semántico y facilitar la movilidad estudiantil por lo menos a nivel nacional.

En síntesis, como reto final emergente de la investigación, se plantea que más allá del sustrato físico y propositivo, la clave en el funcionamiento de toda institución es la gestión y éste es el mayor desafío de las mismas: organizar, disponer, decidir, administrar, controlar, monitorear y evaluar los recursos y las personas con justicia, eficiencia y efectividad para el logro de los objetivos organizacionales que impacten en la transformación de la Educación Superior y al mismo tiempo en la realidad social.

\section{BIBLIOGRAFÍA}

Conferencia Mundial sobre Educación Superior. (2009). Las Nuevas Dinámicas de la Educación Superior y de la Investigación para el Cambio Social y el Desarrollo. UNESCO, París.

Constitución Nacional. (1992, 20 de junio). Poder Legislativo. Asunción. Paraguay.

Congreso de la Nación. (2005). Diagnóstico y propuestas para la Educación Superior en el Paraguay. Asunción: Comisión Bicameral para el estudio de la Reforma de la Educación Superior-Comisión Nacional para la Reforma de la Educación Superior.

Declaración Mundial de Educación Superior: Visión y Acción. (1998). París: UNESCO

DELORS, J. (1996). La educación encierra un tesoro. Madrid: UNESCO -Santillana.

Ley General de Educación $N^{\circ}$ 1264. (1998, 26 de mayo). Poder Legislativo. Asunción. Paraguay.

MORÍN, E. (2001) Los siete saberes necesarios para la educación del futuro. Buenos Aires. Argentina: Ediciones Nueva Visión.

MORÍN, E. (2001). La cabeza bien puesta. Buenos Aires. Argentina: Ediciones Nueva Visión. 
MUNGARAY, A. y VALENTI, G. (1997). Políticas y Educación Superior. México: ANUIES. Recuperado el 3 de setiembre de 2010, de:http://books.google.com.py books?id=buVUn9DCf2gC\&pg=PA7\& $\mathrm{dq}=\mathrm{pol} \% \mathrm{C} 3$

SANZ MENÉNDEZ, L. (2003). La investigación en la universidad española. Conferencia: Universidad de Valencia. Recuperado el 2 de setiembre de 2010, de: http://digital.csic.es/bitstream/ 10261/1568/1/dt0306.pdf

TÜNNERMANN, C. (2003). La universidad ante los retos del siglo XXI. México: Departamento Editorial. Recuperado el 4/9/2010: http:/ /books. google.com.py/ books?id=fK4pqdIhsGkC\&pg=PA8\&dq=la+univers

RAMA, C. (2006). La Tercera Reforma de la Educación Superior en América Latina. México: Fondo de Cultura Económica.

RINESI, E., SOPRANO, G., y SUASNÁBAR, C. (2005). Universidad: Buenos Aires: Prometeo

RIVAROLA, D. (2003). La educación superior universitaria en el Paraguay. Asunción: Ediciones Arte.

URIBE ROLDÁN, J. (2008). Educación terciaria transfronteriza. Una nueva perspectiva para la integración. Santa Fe de Bogotá: Convenio Andrés Bello.

VESSURI, H, (2006), Universidad e Investigación Cientíûca: Convergencias y Tensiones. Buenos Aires, Argentina: Consejo Latinoamericano de Ciencias Sociales. CLACSO. UNESCO. Recuperado 8/9/2010 en: http://bibliotecavirtual.clacso.org.ar/ar/libros/ secret/vessuri/vessuri.html.

ZEBALZA, M. (2002). La enseñanza universitaria. El escenario y sus protagonistas. Madrid: Narcea. 